\title{
In Situ, Non-Destructive Testing for Evaluating the Role of Pointing Mortar in Preventive Conservation Strategies. A Case-Study on Reigate Stone at the Wardrobe Tower, Tower of London
}

\author{
Martin Michette ${ }^{1, *}$, Heather Viles ${ }^{1}$, Constantina Vlachou ${ }^{2}\left(\mathbb{D}\right.$ and Ian Angus ${ }^{3}$ \\ 1 School of Geography and the Environment, University of Oxford, Oxford OX1 3QY, UK; \\ heather.viles@ouce.ox.ac.uk \\ 2 Historic Royal Palaces Conservation and Collections Care Department, Hampton Court Palace, \\ Surrey KT8 9AU, UK; constantina.vlachou@hrp.org.uk \\ 3 Carden \& Godfrey Architects, London EC1R 0AU, UK; iana@cardenandgodfrey.co.uk \\ * Correspondence: martin.michette@ouce.ox.ac.uk
}

Citation: Michette, M.; Viles, H.; Vlachou, C.; Angus, I. In Situ, Non-Destructive Testing for Evaluating the Role of Pointing Mortar in Preventive Conservation Strategies. A Case-Study on Reigate Stone at the Wardrobe Tower, Tower of London. Minerals 2021, 11, 345. https://doi.org/10.3390/min11040345

\section{Academic Editors:}

Antonio Sansonetti, Elisabetta Rosina and Barbara Lubelli

Received: 8 February 2021

Accepted: 21 March 2021

Published: 26 March 2021

Publisher's Note: MDPI stays neutral with regard to jurisdictional claims in published maps and institutional affiliations.

Copyright: (c) 2021 by the authors Licensee MDPI, Basel, Switzerland. This article is an open access article distributed under the terms and conditions of the Creative Commons Attribution (CC BY) license (https:/ / creativecommons.org/licenses/by/ $4.0 /)$.

\begin{abstract}
The correct choice of pointing mortar is considered crucial to the conservation of historic masonry. A proliferation of cement and eminently hydraulic lime mortars since the late 19th century has accelerated the deterioration of built cultural heritage in many parts of the world. Whilst the use of softer, lime-based mortars in stone conservation is now common practice, their role in the overall conservation strategy of highly vulnerable building stones such as Reigate Stone requires assessment. In this paper non-destructive testing (NDT) is used across a two-year period to investigate the impact of different pointing mortar types in situ. NDT data on surface hardness and moisture are interpreted at different scales to assess moisture regulation of Reigate Stone masonry at the Wardrobe Tower, a ruined structure at the Tower of London, following repointing carried out in Spring 2017. Joints repointed using a hydraulic lime mortar (NHL3.5) are shown to regulate moisture in adjacent Reigate Stone blocks less well than those repointed using a lime putty mortar. However, despite an initially inappropriate recipe, older hydraulic lime mortars are in some instances shown to perform similarly to the lime putty mortar, suggesting that NHL can weather sympathetically. The results also indicate that, whilst pointing mortar type does play a role in the moisture regulation of individual stones, its effect is outweighed by both properties of the stone itself, such as strength and past decay, and by wider micro-contextual factors, such as exposure or adjacent topography. Findings from the Wardrobe Tower indicate that pointing mortar only plays a part in overall moisture regulation; to enable its effective functioning and minimise the need for repeated interventions, it may be necessary to take additional protective measures to mitigate moisture ingress, such as water run-off and channelling following heavy rainfall. The overall implication is that in vulnerable historic masonry such as Reigate Stone, sustainable conservation strategies must incorporate a broad appraisal of, and tailored response to, specific decay mechanisms. With careful calibration across repeated survey campaigns, data collected in situ using NDT can inform the role of pointing mortar within such strategies.
\end{abstract}

Keywords: NDT; building materials; monitoring; moisture transport; moisture related decay

\section{Introduction}

Since the 1970s there has been a revival in the use of lime mortars for conservation. However, there are knowledge gaps and persistent misunderstandings as to their correct application, particularly on vulnerable masonry. Whilst the potential damage caused by excessively strong, hydraulic lime mortars is well documented, imprecise specification or product description often results in the use of material that may be unsuitable [1,2]. Furthermore, the properties of a non-hydraulic lime mortar are determined by a wide range of parameters during the production process, and there are ongoing concerns about 
hydraulic lime mortar continuing to harden, in pointing, long after it has apparently set [3]. Recent studies advocate a return to traditional recipes and methods, such as hot lime mixes and wood ash additives (e.g., [4,5]). As in other areas of architectural conservation, improvement of mortar design and application depends on a reciprocity between practice and research. Scientific study has focused on controlled laboratory experiments. These have included assessments of standards and their applicability to conservation practice, sampling strategies for the analysis of historic fabric, and test-wall simulations (e.g., [2,5,6]). Inevitably, the emphasis of these studies is on one aspect of the complex set of interrelated challenges found at any historic site. Conducting science at world heritage sites such as the Tower of London provides an opportunity to investigate how the implementation of research-based protocol affects the management of vulnerable, valuable masonry such as Reigate Stone.

Reigate Stone was mined from the Upper Greensand in North West Surrey and has an unusual mineralogy, with variable amounts of calcite and glauconite $[7,8]$. Commonly referred to as a calcareous sandstone, it has a highly micro-porous matrix of precipitated, crystalline silica (opal-CT), which forms a weak cement for very fine-grained quartz and bioclastic components. Open porosity in stone sampled from buildings ranges from $27 \%$ to $38 \%$. A lack of distinct bedding planes meant it was favoured as a 'freestone' for finely cut masonry, such as ashlar and moulding. It was used extensively in medieval South East England and has long posed a challenge to effective conservation and repair $[9,10]$. Calcareous stone has survived well in many cases, but more vulnerable argillaceous stone has responded poorly to treatment. Recent best conservation practice on Reigate Stone masonry at the Tower of London has involved repointing with lime putty but has not in every case halted rapid decay.

The objective of this research is to establish and test a field protocol for assessing pointing mortar in highly vulnerable, historic masonry. The use of portable, accessible non-destructive testing (NDT) is explored in order to facilitate general practice. Recent re-pointing of the Wardrobe Tower, Tower of London provides an appropriate case study for this purpose. The specific research questions are:

- How can NDT best be used to determine the effect of pointing mortar on surrounding masonry?

- Is there a discernible difference between the performance of different pointing mortar recipes used in Reigate Stone conservation?

- Does pointing mortar constitute a measurable control on the decay of the Wardrobe Tower?

The wider aim is to investigate the complex relationship between pointing mortar and valuable masonry, inform debate on the extent to which repointing can be incorporated into sustainable conservation strategies and provide baselines for the potential improvement of recipes used on highly vulnerable building stones.

\subsection{Pointing Mortars in Building Conservation}

Pointing mortar plays an important role in regulating moisture in masonry structures. During driving rain, exposed stone can absorb large amounts of water [11,12]. Ideally this moisture should be drawn back out through the mortar, rather than evaporating through the face of the stone [13]. This minimises moisture fluctuations at the exposed stone surface, which can drive salt crystallisation cycles and the swelling of clay minerals $[14,15]$. When it is drawn out through the mortar, the moisture instead evaporates through the joints between two stones. The correct functioning of this process depends on various properties of the mortar in relation to the surrounding stone, such as its porosity and plasticity [16]. In the pre-industrial era, locally sourced lime-based mortars were used in many parts of the world and functioned well if they were correctly worked and maintained. Maintenance included regular replacement of decayed pointing mortar which was no longer functional. The pointing mortar can be more easily replaced than the stones themselves and is generally considered sacrificial to this effect. Whilst mortar may have implicit cultural value itself, repointing is, therefore, an important part of the conservation of historic masonry [17]. 
Pointing mortar should neither trap moisture, nor leave masonry unprotected from moisture penetration $[16,18]$. This requires a well-sealed joint without any cracks or fissures, with an unbroken surface contact area between the pointing mortar, the surrounding stone, and the bedding mortar within the joint. The pointing mortar needs to be worked to a consistency and applied in a manner which ensures such surface contact and cover, whilst also being able to deform plastically to maintain contact. Furthermore, the mortar must act as a poultice to the stone, drawing moisture from the pores of the stone into its own porous matrix. This requires a pore-size distribution with a high proportion of interconnected capillaries. Traditional, non-hydraulic lime-based mortars generally fit these requirements, however they proved difficult to work and maintain in damp environments. Hydraulic limes and natural cements began to replace ordinary lime mortars in the mid-18th century [19]. Whilst these could set in damp conditions, the chemistry necessary to enable this hydraulic set frequently resulted in increased brittleness and a denser microstructure more prone to trap moisture. The proliferation of cement-based material from the late 19th century introduced new types of hard, dense mortar into the historic built fabric, which proved inadequate for the effective moisture regulation of historic masonry (e.g., [20,21]).

Repointing occupies an ambiguous space within the practical framework of architectural conservation. It involves an intervention in the masonry system, but the primary functional role is of a sacrificial nature. By regulating moisture exchange with the environment, pointing mortar functions as a mediator between the more permanent elements of a masonry system and the surrounding environment. In this respect, the maintenance of functioning pointing mortar could be considered a preventive conservation strategy. On the other hand, mortar may have significant cultural value itself. It provides documentary evidence and aesthetic complexity [17]. Policy may dictate that mortar recipes for conservation work be specified to match the extant, historic mortar. Occasionally, this can result in a conflict between historic values and best conservation practice. Furthermore, beyond the simple removal of decayed mortar, repointing works can constitute a significant interruption of a masonry system's equilibrium, even when using suitable, lime-based materials. Correct protocol of lime mortar repointing involves a prolonged wetting of the stonework, which can damage vulnerable building stones, and frequently a defrassing (removal of loose material), which is intended to remove moisture traps and reduce frost damage but can expose fresh layers of fabric to new cycles of decay [22]. Removal of hard pointing mortar can damage the ariss (edge) of a stone and widen the joint, increasing the risk of moisture penetration. It is important to weigh up the immediate intervention with any long-term benefit mortar repair can provide. For vulnerable, valuable masonry and in a new era of changing climate, this may require a reappraisal of the complex, dynamic relationship between conservation values and the physics of decay.

\subsection{Non-Destructive Testing (NDT)}

NDT provides a vital opportunity for the in situ examination of historic masonry. The term refers to a wide range of portable techniques that can be used to examine certain material properties without the need for destructive sampling. These include high-tech approaches, such as imaging and radar methods that have migrated from civil engineering and archaeology (e.g., $[23,24])$, and the use of spectrometric instruments previously confined to laboratories (e.g., $[25,26])$. In many cases such techniques will prove to be unaffordable or impractical for historic masonry conservation projects $[27,28]$. A range of low-cost techniques such as surface peeling and water uptake methods also exist (e.g., [29,30]). These can be more applicable to general practice whilst still delivering meaningful data; however, establishing user-friendly protocols for enabling comparison of these methods across different studies is proving challenging (e.g., [31]). Somewhere in between sit a variety of hand-held devices which have found increasing success in measuring or approximating certain material properties. These include instruments for measuring surface hardness [32,33] and moisture content [34,35]. 
Recent studies have used NDT to monitor decay rates and assess conservation strategies. Surface hardness has been related to a variety of material properties, such as strength [36,37] and porosity [38], and measurements can be used to indicate decay [32,39]. Wilhelm et al. [33] investigated the statistical confidence of using a low impact hardness tester. Their findings suggest large datasets are necessary to enable a robust analysis, which should also consider statistical outliers. Hand-held moisture meters function according to a variety of different electro-magnetic principles [35,40]. Whilst some of these have found use in practice, gathering and interpreting data requires care [34]. Many NDT, and hand-held moisture meters in particular, use abstract or proxy units. In some cases, these cannot be compared across different material surfaces; NDT requires careful calibration in order to interpret results of general significance.

Care must also be taken to define the scale of investigation. Distinguishing between rapid and in-depth NDT protocols is vital to producing meaningful datasets. NDT can be used to support broad conceptual arguments (e.g., [41]) or investigate the need for further surveys (e.g., [42]). In these cases, small datasets based on individual point readings can suffice and calibrating measurements in controlled environments is not always necessary; the NDT is used to highlight spatial or temporal patterns. In other cases, NDT can be used to gather empirical data and linked to specific material properties. This demands more rigorous and robust protocols (e.g., [33,43]). An in-depth approach may benefit from combining two or more NDTs in order to triangulate results (e.g., [27,38]), and calibration with laboratory tests (e.g., [44]). Provided data is collected accordingly, NDT can be useful for both rapid field surveys and in-depth, data rich analysis.

\section{Site and Methods}

\subsection{Wardrobe Tower}

\subsubsection{Construction and Conservation}

The Wardrobe Tower was selected for this study because it was recently repointed in accordance with accepted Reigate Stone conservation protocol, and because of a rich and relatively well documented history of past use and repair. It was built in 1190 as an annexe to the White Tower, directly on the remains of a Roman mural tower, with Reigate and Caen stone ashlar and a rubble core [45]. Throughout the medieval and early modern period, a dense cluster of buildings grew around the White Tower (Figure 1A). Between 1879 and 1885 the south eastern annexe was removed in line with the stylistic notion of the era to restore the Tower to 'its original condition' [46]. Much of the Wardrobe Tower was destroyed until remnants of medieval and Roman masonry were uncovered and preserved. Its present-day condition is ruinous, with only a small area of the south facing elevation surviving. The Wardrobe Tower is especially important for its historical and evidential value, with strong links to both the Tower and the city present in its material record and its illustration of architectural function [47].

There is evidence of historic repair and conservation work in the material fabric and documentary history of the Wardrobe Tower (Figure 1B). Several stones exhibit decay features which clearly predate their current location, indicating recycling of material during the original construction or early repair of the tower. Historic records show work was carried out to the Wardrobe Tower in 1532 and 1673-4 [48]. Repairs in 18th century red brick are also evident. Since its partial demolition in the 1880s, remnants of a coarse render and a patchwork of pointing mortars suggest conservation work was carried out on several occasions. Records indicate 'lime-method' repairs were carried out in 1995 by St Cuthbert Conservation, London. In total at least four different historic pointing mortars are evident. 


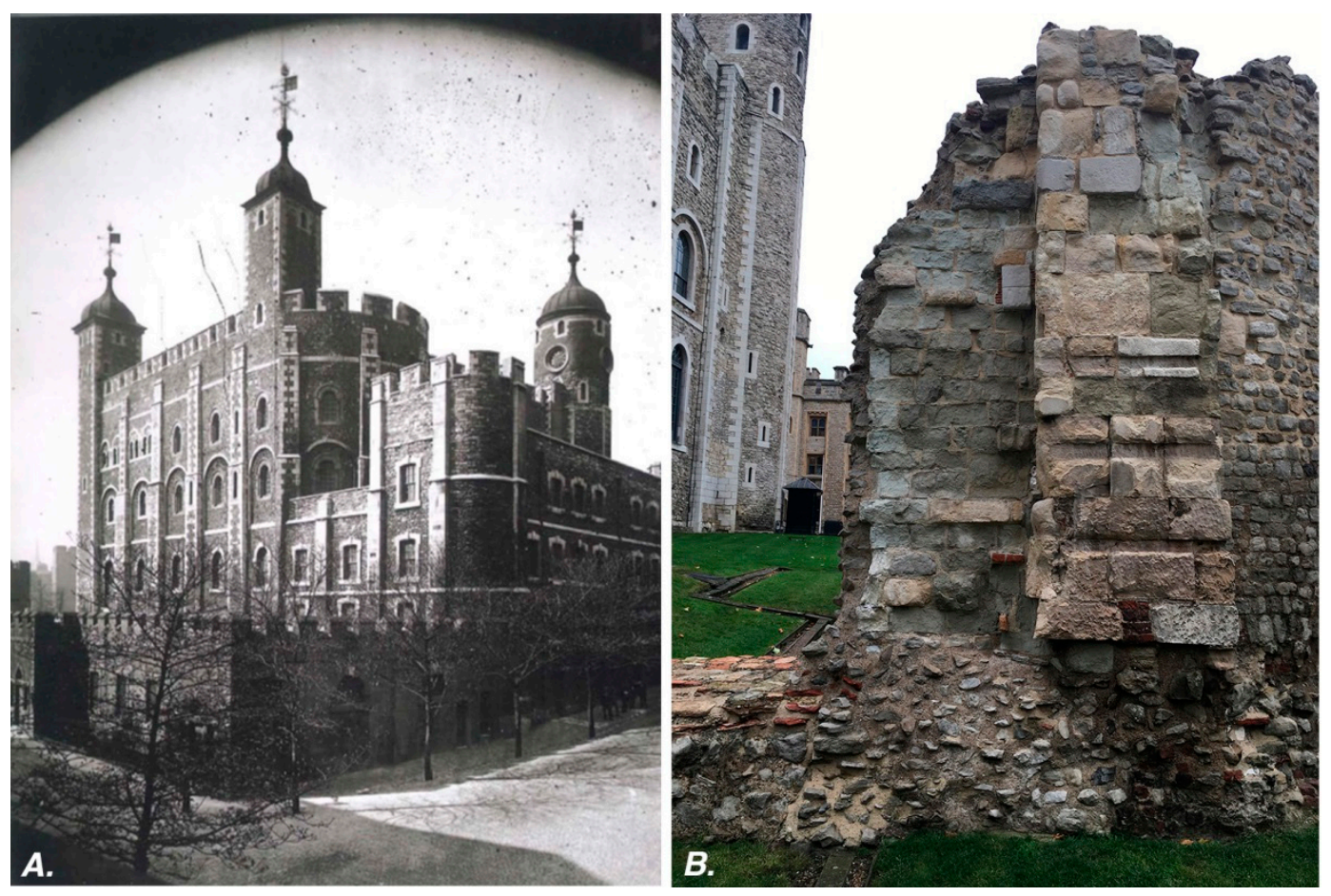

Figure 1. (A) Extent of late- and post-medieval auxiliary construction surrounding White Tower (main building) and Wardrobe Tower (foreground). Photo from south-east c.1870 (HRP archives). (B) Present-day condition of Wardrobe Tower, following 2017 conservation work, viewed from south. Photo November 2017 (Authors own).

In April/ May 2017 conservation work was commissioned by Historic Royal Palaces (HRP) and carried out by Carden and Godfrey Architects in line with the protocol adopted at HRP sites and elsewhere, focusing on cleaning of the masonry, removal of damaging materials, mechanical consolidation and sensitive lime mortar repair. Ashlar masonry was subjected to careful soft brushing to remove any exfoliated fragments or flaking surface crusts. Most of the remaining coarse render was removed at this stage. This was followed by variable pressure steam cleaning of all surfaces. Selective depointing was performed to $50-75 \%$ of ashlar masonry, focussing on the removal of mortar standing proud around eroded stone and hard cement mortar. Loosened masonry was re-bedded where possible; tile supports and stainless-steel pins were added if structurally necessary. Repointing was performed with a lime putty mortar mixed from 1 part mature fat lime putty (Singleton Birch), 2.5 parts sand and 0.5 parts gravel (up to $4 \mathrm{~mm}$ ). The sands were a mixture of granular size and source, from soft fine to sharp to coarse sharp, varied according to joint size, but with the mortar ratio always the same. For the purposes of this study, two areas of approximately $1 \mathrm{~m}^{2}$ paired across a section of the wall were repointed with a moderately hydraulic natural hydraulic lime mortar (NHL 3.5) (Singleton Birch) using the same mixing proportions.

\subsubsection{Present Condition}

An initial assessment of the Wardrobe Tower was conducted between March and May 2017. The objective was to identify Reigate Stone locations and define and determine relative condition, identify pointing mortar types and locations, and assess the immediate impact of conservation work. Whilst there are isolated Reigate Stone blocks spread across the monument, large areas of Reigate masonry are restricted to the following locations (Figure 2): 


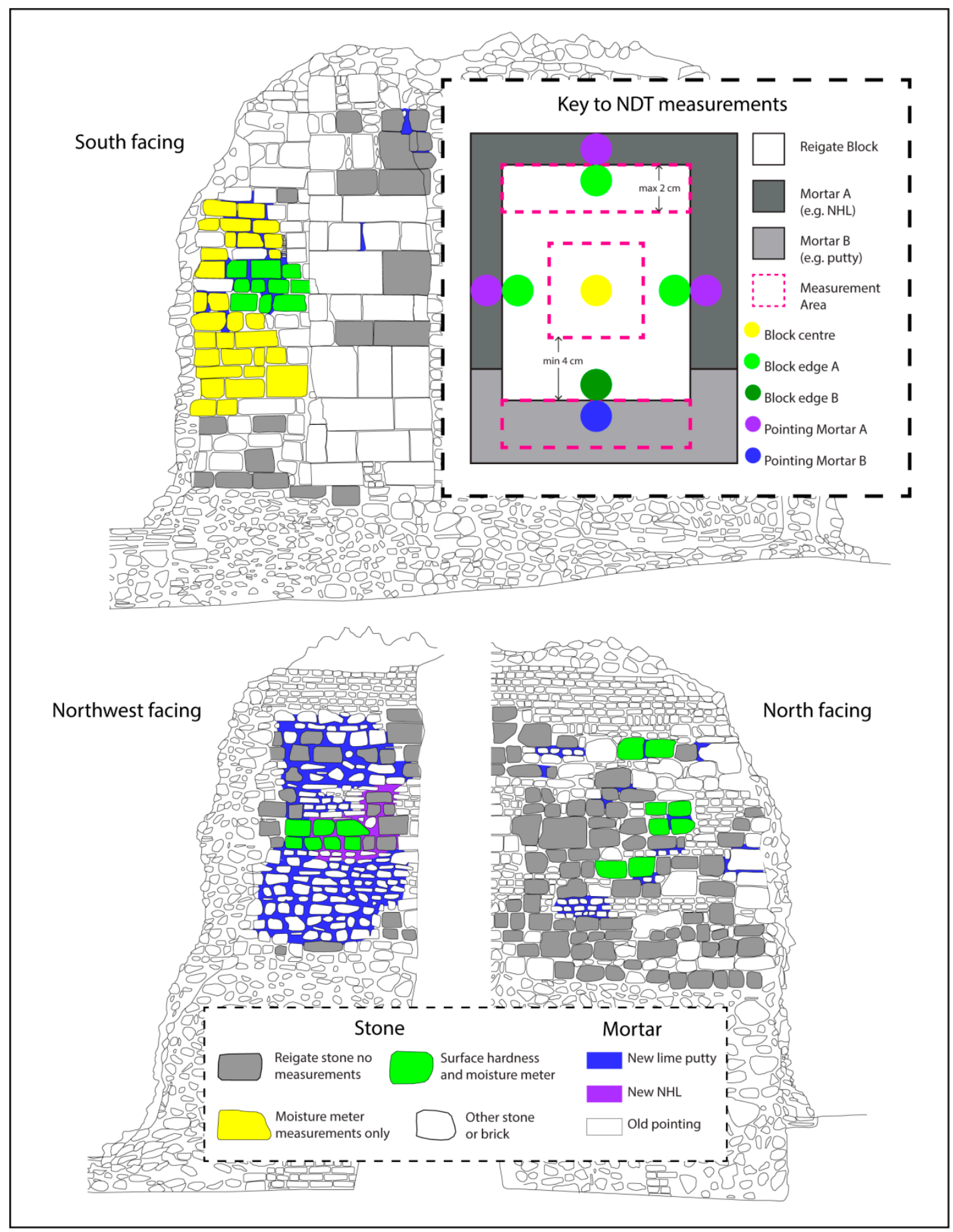

Figure 2. Schematic views of Wardrobe Tower showing distribution of Reigate Stone and areas of non-destructive testing (NDT) measurements in field surveys. Inset shows methodology of NDT measurements (used on dark blue blocks), with dotted squares describing regions in which joint, block edge and block centre measurements were taken. Between 1 and 8 measurements were taken for each circle, depending on survey date and device used.

- The entire western flank of south facing ashlar masonry. The upper part of this area was more extensively repointed in 2017; the lower part was left with extant pointing mortar, believed to date to the 1995 work.

- An area of ashlar interspaced with brick courses at the upper eastern flank of north facing masonry. This area was almost entirely repointed in 2017, and it includes the area repointed with NHL. 
- A large area of ashlar and rubble interspaced with brick courses and other stone types, covering the upper half of the central and western parts of north facing masonry. This area was only partially repointed in 2017 and contains a patchwork of older pointing mortars.

Different patterns of Reigate Stone decay are evident, including cracking, flaking, powdering and discolouration, alongside different rates of material loss. There is evidence of widespread salt contamination. All Reigate masonry shows signs of decay, however there is no immediately clear correlation between rates or patterns of decay and exposure, aspect, height or material context. The 2017 work removed large areas of proud mortar. In some cases, larger fragments of stone were removed along edges, leading to a widening of mortar joints. Despite removal of friable material, the surface of many stones still displayed signs of flaking or powdering; efflorescence was visible across many stones, particularly on freshly exposed surfaces. Isolated proud or poorly bonded mortar joints remain. Whilst the hardest, cementitious pointing mortars are now limited to just a few areas of Reigate masonry, they continue to dominate other parts of the structure, including the cap, the exposed rubble core at the outer flanks and the rubble batter at the base of the masonry.

\subsubsection{Material Composition}

Samples of different historic pointing mortars were taken from material that was removed during the 2017 conservation work. The initial on-site differentiation of these samples was based on visual and haptic assessment. Small samples of the original bedding mortar were carefully removed from within freshly exposed joints. Isolated samples of Reigate Stone that became detached from an area of south facing masonry during the conservation work were also collected. To assist with the in situ material characterisation and analysis that make up the main part of the study presented here, optical microscopy was performed on thin sections impregnated in blue resin (Olympus BX43, Olympus, Tokyo, Japan). The bedding mortar and two historic pointing mortars were analysed using an FEG Quanta 250 Scanning Electron Microscope (FEI, Hillsboro, OR, USA) coupled with a Pegasus APEX Energy-Dispersive X-ray spectroscope (Ametek EDAX, Berwyn, PA, USA). Images were taken in back-scattered electron mode (BSE) at $20 \mathrm{kV}$ with a spot size of $4.0 \mathrm{~nm}$. Thin sections were un-spattered and observed in low-vacuum mode.

The original bedding mortar (Figure $3 \mathrm{~A}$ ) is a highly porous lime mortar with aggregate from quartz, small fragments of hardened lime mortar, and occasional brick. The binder is pure air lime, calcined from a foraminifera limestone. Short-time or low-temperatures of calcination caused large lumps of raw feed stone which has in part kept the original texture. The high lime content, visible as a microcrystalline mass that makes up the bulk of the material (Figure 3B), provides a high, interconnected microporosity. The shrinkage cracks may reflect that the mortar was still moist when samples were extracted. The first historic pointing mortar (Figure 3C) is a compact mortar with aggregate of rounded quartz, iron-oxide siltstone grains, and minor amounts of alkali feldspar and occasional slate. Typical grain size of aggregate is 0.4 to $1 \mathrm{~mm}$, maximum $3 \mathrm{~mm}$. It is relatively lean, but the fabric is binder-supported (no contact between aggregates). The binder is cementitious, though Ca-silicate clinker remnants are rare and no alite can be found. The temperature of calcination of the binder was generally below, or in the lower stages, of sintering (Figure 3D). It appears highly carbonated, with secondary calcium carbonate dispersed in a silica-rich matrix. Capillary porosity is low, a consequence of the intense carbonatation. Occasional air voids are in the range of max. $1 \mathrm{~mm}$ in size. It could be a natural cement, or an early, artificial ('Proto-Portland') cement dating to the early 19th century. The other historic pointing mortar (Figure 3E) is a porous mortar with gravel and sand aggregate of quartz and occasional iron-oxide grains. Typical grain size of aggregate 0.4 to $0.5 \mathrm{~mm}$, maximum $6 \mathrm{~mm}$. It is relatively lean, but the fabric is binder-supported (no contact between aggregates). Compared to the first, the binder is relatively porous; capillary porosity seems to be high with almost no air voids. The binder is cementitious, Ca-silicate clinker remnants are abundant (Figure 3F), but due to their composition (mostly 
in the range of rankinite, a non-reactive low-temperature precursor of belite) the binder was not able to hydrate sufficiently for the development of a dense and strong fabric. Free lime is missing, as are typical features of a natural NHL raw feed, suggesting it could be a 'hybrid' mixture of the type used in the 1908s and 90s [17].
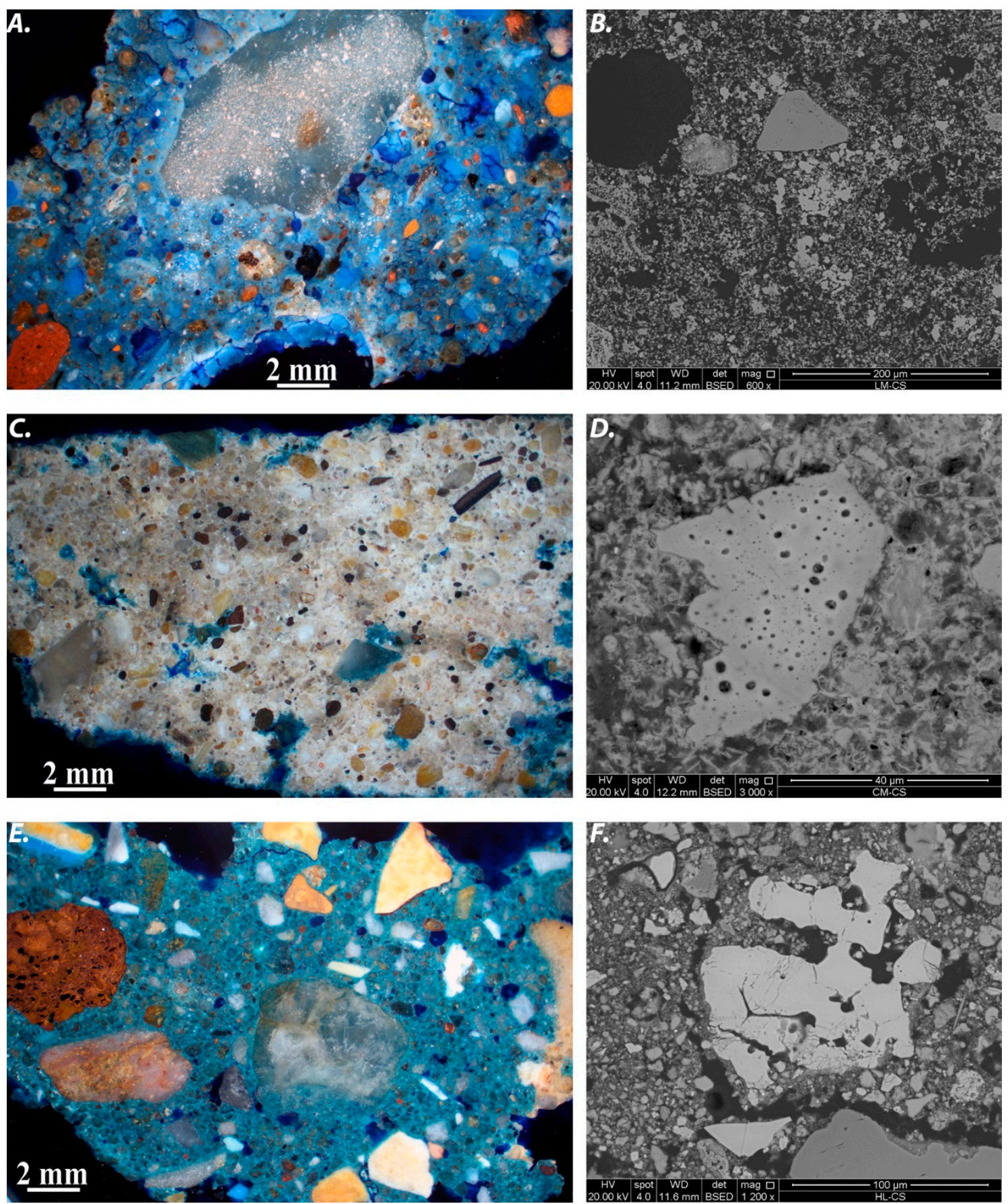

Figure 3. Optical (left) and scanning electron microscopy (SEM, right) micrographs of mortars collected from Wardrobe Tower during 2017 conservation work. (A) Original bedding mortar (BM), showing (B) porous lime binder with partly recrystallized calcite. (C) Probable early 19th-century pointing mortar (HM3), with (D) residual calcite indicating low temperature of calcination. (E) Probable late 20th-century pointing mortar, with (F) large crystal of rankinite. Note differing scale bars for SEM images.

The bedding mortar is likely to have a pore-size distribution that will enable an effective poulticing and moisture regulation of adjacent Reigate Stone. Although the 
pointing mortars will have differing hygroscopic properties, they could both be classified as eminently hydraulic, and they would not be considered suitable recipes for contemporary conservation work. Small remnants of both softer lime mortars, and harder, pure Portland cement mortars were present in areas of Reigate Stone masonry, however the two mortars analysed here are likely to be representative of the majority of old mortar joints. Samples of Reigate Stone included remnants of attached mortar, making it possible to produce thin sections across the stone-mortar interface (Figure 4). These reveal dissolution of the highly micro-porous, opal-CT matrix of the Reigate Stone, with a $0.5 \mathrm{~mm}$ band of increased stone porosity visible under a dense, poorly bonded mortar. This suggests the mortar may be trapping moisture and salts at the stone edge, which is playing a significant role in the decay pathway of the masonry.

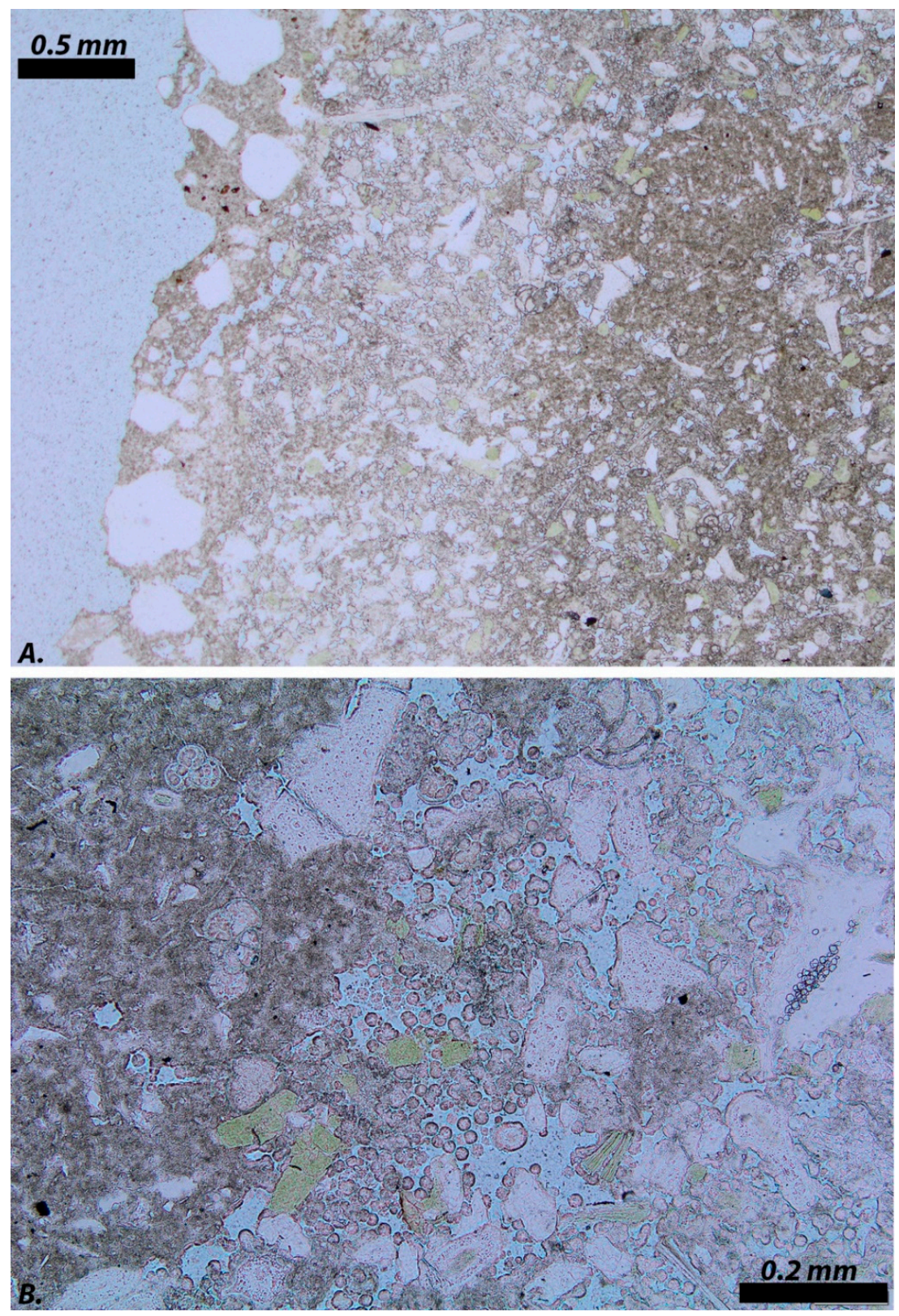

Figure 4. Optical micrographs of material collected from Wardrobe Tower during 2017 conservation work showing interface of Reigate Stone (right) and a hard mortar (left). (A) A porous band of Reigate Stone sits between mortar and denser, underlying stone fabric. (B) The bond is poor, and the stone fabric displays a high level of dissolution. 


\subsection{Methodology}

\subsubsection{Field Surveys}

Five detailed surveys campaigns using on-site NDT were conducted over a twoyear period at the Wardrobe Tower, Tower of London. The surveys were conducted in November 2017, May 2018, August 2018, January 2019 and September/ October 2019. Survey dates were planned to acquire data during different environmental conditions. The aim was to assess the role of pointing mortar in the decay of Reigate Stone masonry, by correlating moisture dynamics with different mortar types. Reigate Stone ashlar blocks spread across the Wardrobe Tower were selected for surveying, to reflect the following variables (Figure 2):

- Type and condition of pointing mortar. Condition was initially determined based on bond, width and profile. Type was defined as one of three categories:

1. New lime putty mortar used in April 2017 conservation.

2. New NHL applied to test area in April 2017.

3. Old pointing mortar. Treated as one group. In situ differentiation of pointing mortars was not always possible due to discolouration. Two historic mortars analysed in previous section likely to be representative of joints surveyed.

- Contextual factors, including aspect, height and adjacent masonry.

A meteorological station (Vaisala, Finland) positioned on the nearby Bell Tower recorded ambient temperature and relative humidity $(\mathrm{RH})$, as well as rainfall, solar radiation, and wind direction and speed over the two-year period. These data were used to construct wetting and drying profiles for the time period prior to each survey (Table 1).

Table 1. Summary of field survey dates showing wetting and drying scenarios.

\begin{tabular}{|c|c|c|c|c|}
\hline Survey Date & $\begin{array}{l}\text { Summary of } \\
\text { Environmental } \\
\text { Conditions }\end{array}$ & $\begin{array}{c}\text { Conditions in Preceding } \\
\text { 2-Week Period }\end{array}$ & $\begin{array}{l}\text { Most Recent Rainfall and } \\
\text { Wind Direction before } \\
\text { Survey }\end{array}$ & $\begin{array}{l}\text { Drying Conditions } \\
\text { during Survey }\end{array}$ \\
\hline $\begin{array}{l}\text { November } 2017 \\
14.11-16.11 .17\end{array}$ & $\begin{array}{l}\text { Prolonged wetting } \\
\text { and poor drying }\end{array}$ & $\begin{array}{l}\text { Relative humidity }(\mathrm{RH}) \\
\text { above } 70 \% \text {, temperature } \\
\text { around } 10^{\circ} \mathrm{C} \text {. } \\
\text { Repeated rainfall. }\end{array}$ & $\begin{array}{c}\text { Series of heavy spells on the } \\
10.11 \text { and } 11.11 \text {, in which a } \\
\text { total of } 18 \mathrm{~mm} \text { fell (peaking } \\
\text { at } 8 \mathrm{~mm} \text { in one hour). } \\
\text { Light winds. }\end{array}$ & $\begin{array}{l}\text { Temp and RH stable. } \\
\text { Average solar radiation } \\
\text { was } 100-150 \mathrm{~W} / \mathrm{m}^{2} \text {. } \\
\text { Light rainfall. }\end{array}$ \\
\hline $\begin{array}{c}\text { May } 2018 \\
3.05-4.05 .18\end{array}$ & $\begin{array}{l}\text { Prolonged wetting } \\
\text { and good drying }\end{array}$ & $\begin{array}{c}\mathrm{RH} \text { above } 70 \%, \\
\text { temperatures around } \\
10{ }^{\circ} \mathrm{C} \text {. Prolonged rainfall. }\end{array}$ & $\begin{array}{l}\text { Heavy, wind driven spell in } \\
\text { which } 5 \mathrm{~mm} \text { fell in } 5 \mathrm{~h} \text { on } \\
\text { 2.05. Wind direction varying } \\
\text { from } \mathrm{S} \text { to } \mathrm{NWW} \text { at speeds of } \\
\text { up to } 5 \mathrm{~m} / \mathrm{s} \text {. }\end{array}$ & $\begin{array}{c}\mathrm{RH} \text { below } 70 \% \text {, } \\
\text { daytime temperature } \\
\text { rose to } 20^{\circ} \mathrm{C} \text {, with } \\
\text { average solar radiation } \\
\text { of } 500-600 \mathrm{~W} / \mathrm{m}^{2} \text {. } \\
\text { No rainfall. }\end{array}$ \\
\hline $\begin{array}{l}\text { August } 2018 \\
12.08-13.08 .18\end{array}$ & $\begin{array}{l}\text { Rapid, heavy } \\
\text { wetting and } \\
\text { good drying }\end{array}$ & $\begin{array}{l}\mathrm{RH} \text { under } 80 \% \text {, daytime } \\
\text { temperatures between } 20 \\
{ }^{\circ} \mathrm{C} \text { and } 30^{\circ} \mathrm{C} \text {. No rainfall } \\
\text { before } 09.08 .\end{array}$ & $\begin{array}{l}\text { Heavy, wind-driven rain on } \\
9.08 \text { and } 10.08 \text {, with } 25 \mathrm{~mm} \\
\text { falling in a series of spells } \\
\text { with SSW wind direction } \\
\text { (peaking at } 8.5 \mathrm{~mm} \text { in } 20 \text { min } \\
\text { with wind speeds of } \\
\quad 6.5 \mathrm{~m} / \mathrm{s} \text { ). }\end{array}$ & $\begin{array}{l}\text { Daytime temperature } \\
18^{\circ} \mathrm{C} \text { with average } \\
\text { solar radiation of } \\
250-300 \mathrm{~W} / \mathrm{m}^{2} \text {. } \\
\text { No rainfall. }\end{array}$ \\
\hline $\begin{array}{c}\text { January } 2019 \\
20.01-22.01 .19\end{array}$ & $\begin{array}{l}\text { Mild wetting and } \\
\text { poor drying }\end{array}$ & $\begin{array}{l}\text { RH mostly above } 70 \%, \\
\text { temperature below } 10^{\circ} \mathrm{C} \text {. } \\
\text { Little rainfall. }\end{array}$ & $\begin{array}{l}2 \mathrm{~mm} \text { falling on } 16 \text { th and } \\
17 \text { th January in a series of } \\
\text { light spells. }\end{array}$ & $\begin{array}{l}\text { Temp and RH stable. } \\
\text { Average solar radiation } \\
\text { was } 150-250 \mathrm{~W} / \mathrm{m}^{2} \text {. }\end{array}$ \\
\hline $\begin{array}{l}\text { October } 2019 \\
30.09-2.10 .19\end{array}$ & $\begin{array}{l}\text { Recent, mild } \\
\text { wetting }\end{array}$ & $\begin{array}{l}\text { Variable } \mathrm{RH}, \\
\text { temperatures between } 15 \\
\text { and } 20^{\circ} \mathrm{C} \text {. Occasional } \\
\text { light showers. }\end{array}$ & \multicolumn{2}{|c|}{$\begin{array}{l}\text { Several light rain spells on the first two days of the } \\
\text { survey, with varying wind direction and speed up to } \\
55 \mathrm{~m} / \mathrm{s} \text {. }\end{array}$} \\
\hline
\end{tabular}

Non-destructive techniques were used to investigate surface hardness ( $\mathrm{SH}$ ) and moisture content $(\mathrm{MC})$, in order to monitor seasonal change in response to environmental variations across repeat surveys and total change across the two-year period. Point measurements to determine $\mathrm{SH}$ and $\mathrm{MC}$ were taken at the centres (at least $4 \mathrm{~cm}$ from any 
mortar joints) and edges (within $2 \mathrm{~cm}$ of closest mortar joint) of 25 individual blocks of comparable size (10-16 cm in height, 12-20 cm in width) from across the structure, and along adjacent mortar joints (Figure 2 inset). Thirty additional south-facing blocks were measured to determine MC only.

Individual blocks and Reigate masonry areas were photographically documented across separate surveys in order to assess visual indicators of decay. Particular attention was placed on assessing the effect of topographical features and different mortar joint scenarios on indicators of moisture uptake, such as biological growth. These effects were monitored at the monument scale and the scale of individual blocks or groups of blocks. A USB microscope (Dino-Lite Edge AM7915MZT, AnMo Electronics, Taiwan) was used to further investigate areas of interest at the micro-scale along stone edges and mortar joints.

\subsubsection{Non-Destructive Testing (NDT)}

Several NDT were trialled in this survey, including colorimetric surface measurements and thermal imaging as a proxy for change in $\mathrm{MC}$, ultrasound measurements and peeling tests [49] as a proxy for fabric strength, and Karsten Tubes to measure water uptake on stone surfaces and at mortar joints. Trials were also made using moisture meters based on conductivity measurements. Conductivity/resistivity measurements can be taken at different depths and used to construct moisture profiles but are highly susceptible to salinity (e.g., [43]). Capacitance devices are less susceptible but can be affected by moisture gradients and decrease in accuracy at high MC [35]. Several of these techniques had previously been successfully used in rapid in situ or laboratory surveys of Reigate Stone as part of a wider research project $[7,9,50]$, but they proved too time-consuming or imprecise to deliver useful datasets for the scale of this survey.

Surface hardness and capacitance moisture meter devices were chosen to conduct the full survey campaigns. These techniques were used in several studies as part of the wider research project. Surface hardness was measured on a range of different Reigate Stone subtypes to link physical characteristics with mineral composition [21]. Both surface hardness and capacitance moisture meters were used in rapid in situ studies linking decay patterns to microclimate [50] and assessing past conservation treatments [22]. The use of these techniques in previous and parallel studies increased the confidence in protocol and results.

Two hand-held capacitance moisture meters (T660, Trotec, Germany and CEM, Shenzhen Everbest Machinery, China) were used to investigate drying rates under different conditions (It was necessary to use different devices due to instrument availability within the timeframes in which surveys were possible at the Tower of London.). Capacitance moisture meters provide a reference value for $\mathrm{MC}$ based on the dielectric constant of a material [35]. This can make comparisons between different materials, or even different areas of inhomogeneous material, difficult. Capacitance meters are also affected by salts, but not as strongly as conductivity meters [51]. Whilst an imprecise method of measuring absolute MC, they have been shown to be effective at determining relative spatial and temporal moisture distribution on the same material. Whilst microwave based non-invasive measurement methods may be more reliable, capacitance devices were chosen because they are cheaper and more widely available and offer a more immediate benefit to the development of practical frameworks. Field surveys were conducted $24-48 \mathrm{~h}$ after rainfall in order to investigate drying rates under different environmental conditions. Table 2 provides a breakdown of moisture meter measurements and areas across the separate surveys. 
Table 2. Summary of moisture meter surveys, showing areas surveyed, types of analysis performed on data, and number of measurements made. Also includes distribution of measurements according to material variables.

\begin{tabular}{|c|c|c|c|c|c|c|c|c|}
\hline \multirow{2}{*}{ Survey } & \multirow{2}{*}{ Areas } & \multirow{2}{*}{ Used for } & \multirow{2}{*}{$\begin{array}{c}\text { Total } \\
\text { Blocks }\end{array}$} & \multirow{2}{*}{$\begin{array}{l}\text { Total } \\
\text { Number }\end{array}$} & \multirow{2}{*}{ Stone $\mathbf{n}$} & \multicolumn{3}{|c|}{ Mortar Number } \\
\hline & & & & & & NHL & Put & Old \\
\hline Nov 17 & S.1; N.1; NW.1 & Calibration & 18 & 122 & 90 & 10 & 8 & 14 \\
\hline May 18 & $\begin{array}{l}\text { S.1; N.1; N.2; N.3; } \\
\text { NW.1 }\end{array}$ & $\begin{array}{l}\text { Calibration; Spatial } \\
\text { distribution (micro) }\end{array}$ & 12 & 355 & 180 & 21 & 74 & 80 \\
\hline Aug 18 & S.1; S.2; N.1; NW.1 & $\begin{array}{l}\text { Calibration; Spatial distribution } \\
\text { (micro and macro) }\end{array}$ & 51 & 656 & 447 & 51 & 87 & 71 \\
\hline Jan 19 & $\begin{array}{l}\text { S.1; S.2; N.1; N.2; } \\
\text { N.3; NW.1 }\end{array}$ & $\begin{array}{l}\text { Calibration; Spatial distribution } \\
\text { (micro and macro) }\end{array}$ & 55 & 555 & 507 & 36 & 57 & 90 \\
\hline Oct 19 & S.2 & Spatial distribution (macro) & 30 & 132 & 132 & & n.a. & \\
\hline
\end{tabular}

Laboratory tests were performed using the two capacitance moisture meters on two large blocks of Reigate Stone from different sources, in order to calibrate measurements and enable a better interpretation of results of the field surveys. The blocks were oven dried, weighed, fully saturated and re-weighed in order to determine saturated MC gravimetrically. The blocks were stored in stable environmental conditions and reweighed at daily intervals to determine saturation. Six readings were taken with each capacitance meter from the same points after each weighing. These calibration trials indicate the response of both moisture meters to different levels of saturation is broadly comparable. High or maximum readings correspond to a saturation of over $90 \%$ and readings then decrease in two steps, which may indicate a transition from the first to the second drying phase. However, individual values are not directly comparable between the devices or necessarily across different Reigate Stone blocks without transformation (because of differences in material properties etc.). Based on these calibrations and complexities, moisture meter measurements made during the field surveys were sorted into three categories. All readings from an individual moisture meter across every survey were grouped and then sorted into three subsets with an equal number of values. For both moisture meters, the upper quantile was close to or at the maximum reading (100 for CEM, 199 for T660). The three categories, therefore, represent maximum values (saturated or close to saturation), high values (wetter) and low values (drier). This enabled an approximate comparison of most wet and most dry areas across different surveys and different areas of masonry.

SH was measured across three different surveys using an Equotip rebound hammer (Probe D on Equotip 550 and Equotip Piccolo, Proceq, Switzerland). The single impact method was used to determine mean values for each block centre or edge with between five and eight scattered readings, which translated to $25+$ readings per block. Table 3 provides a break-down of Equotip measurements and areas across the separate surveys. SH has been shown to provide a useful proxy for a range of different rock properties [39,52]. These include porosity, strength, MC and surface change. Laboratory trials on Reigate Stone found that $\mathrm{SH}$ was sensitive to MC; however, physical characteristics of the stone such as porosity and mineralogy were a greater determinant. A range of interdependent factors are likely to influence Equotip measurements in-situ and they can provide a useful measure of condition. Equotip measurements taken on Reigate Stone are prone to a disproportionally high number of error readings. At the Wardrobe Tower, this was particularly found to be the case on the frequently powdering and flaking surfaces; up to four out of five readings returned errors on some surfaces. Measurements below 200 Leeb hardness (HLD) were omitted from the results as likely to be unrepresentative artefacts caused by surface instability. 
Table 3. Summary of surface hardness surveys, showing areas surveyed, types of analysis performed on data, and number of measurements made. Also includes distribution of measurements according to spatial and material variables.

\begin{tabular}{|c|c|c|c|c|c|c|c|c|c|c|c|c|c|}
\hline \multirow{3}{*}{ Survey } & \multirow{3}{*}{ Areas } & \multirow{3}{*}{ Used for } & \multirow{3}{*}{$\begin{array}{l}\text { Total } \\
\text { Blocks }\end{array}$} & \multirow{3}{*}{$\begin{array}{c}\text { Total } \\
\text { Number }\end{array}$} & \multicolumn{6}{|c|}{ Stone $\mathrm{n}$} & \multicolumn{3}{|c|}{ Mortar n } \\
\hline & & & & & \multicolumn{4}{|c|}{ By Type } & \multicolumn{2}{|c|}{ By Aspect } & \multirow{2}{*}{\multicolumn{2}{|c|}{ NHL Put }} & \multirow{2}{*}{ Old } \\
\hline & & & & & Centr & NHL & Put & Old & $\mathbf{N}$ & $S$ & & & \\
\hline Nov 17 & $\begin{array}{l}\text { S.1; N.1; } \\
\text { NW.1 }\end{array}$ & $\begin{array}{l}\text { Calibration; } \\
\text { ANOVA }\end{array}$ & 18 & 710 & 90 & 70 & 135 & 155 & 280 & 170 & 50 & 85 & 125 \\
\hline May 18 & $\begin{array}{l}\text { N.1; N.2; } \\
\quad \text { N.3 }\end{array}$ & Calibration & 10 & 494 & 110 & n.a. & 224 & 160 & 494 & n.a. & & n.a. & \\
\hline Aug 18 & $\begin{array}{l}\text { S.1; N.1; } \\
\text { NW.1 }\end{array}$ & $\begin{array}{c}\text { ANOVA; } \\
\text { Spatial } \\
\text { distribution }\end{array}$ & 21 & 1410 & 174 & 162 & 264 & 270 & 570 & 300 & 126 & 228 & 186 \\
\hline Jan 19 & $\begin{array}{c}\text { S.1; N.1; } \\
\text { N.2; N.3; } \\
\text { NW.1 }\end{array}$ & $\begin{array}{c}\text { ANOVA; } \\
\text { Spatial } \\
\text { distribution }\end{array}$ & 22 & 1009 & 129 & 123 & 173 & 221 & 436 & 210 & 72 & 112 & 179 \\
\hline Oct 19 & \multicolumn{2}{|c|}{ Not used } & & & & & n.a. & & & & & & \\
\hline
\end{tabular}

\section{Results and Discussion}

\subsection{Overview}

The following section presents and interprets the results of the field surveys and assesses the role of pointing mortar in moisture regulation at the Wardrobe Tower. It begins by analysing the capacitance meter measurements at two scales. The local distribution of measurements at the stone scale across three separate surveys is analysed. This evaluates variation within individual stones which may be attributable to micro-contextual features, such as the width or type of mortar joint. The general distribution of measurements across three separate surveys is then analysed at the monument scale, in order to identify patterns relating to macro-contextual influence, such as the height of the masonry. Following on from this, the Equotip measurements are also investigated at two scales. The general distribution of all measurements across three surveys is statistically analysed using a series of factorial ANOVA (analysis of variance) tests. This evaluates the significance of varying weather, aspect and mortar type in the overall distribution of surface hardness measurements. The local distribution of surface hardness at the stone scale across two separate surveys is then investigated, in order to assess the role of micro-contextual factors more closely. Finally, the photographic and micrographic documentation is used to examine visual indicators of the micro- and macro-contextual determiners identified using the NDT.

Table 1 summarises the environmental conditions that characterised the field surveys. The individual surveys present a range of wetting and drying scenarios with which to assess relative change in the properties of the masonry, as measured using the NDT methods. They also serve to highlight the variety of decay mechanisms affecting the Wardrobe Tower, including heavy driving rain, prolonged deep wetting and fluctuating surface conditions.

\subsection{Capacitance Meter Measurements}

\subsubsection{Local Distribution}

Figure 5 maps the distribution of moisture meter readings across different survey dates and areas, along with type and size of mortar joint and adjacent masonry. Three readings at each centre and edge of individual Reigate blocks are averaged and resulting values are sorted into groups. The May 2018, August 2018 and January 2019 surveys were selected as being reflective of three different wetting and drying scenarios. Edge readings are interpreted as being more likely to be affected by adjacent pointing mortar, due to differences in localised moisture ingress or subsequent poulticing effects. This produces few patterns which directly relate moisture distribution or drying rates across Reigate Stone surfaces to pointing mortar type. However, the overall effect of the different wetting 
and drying scenarios can be observed, and the influence of exposure and material context is apparent.

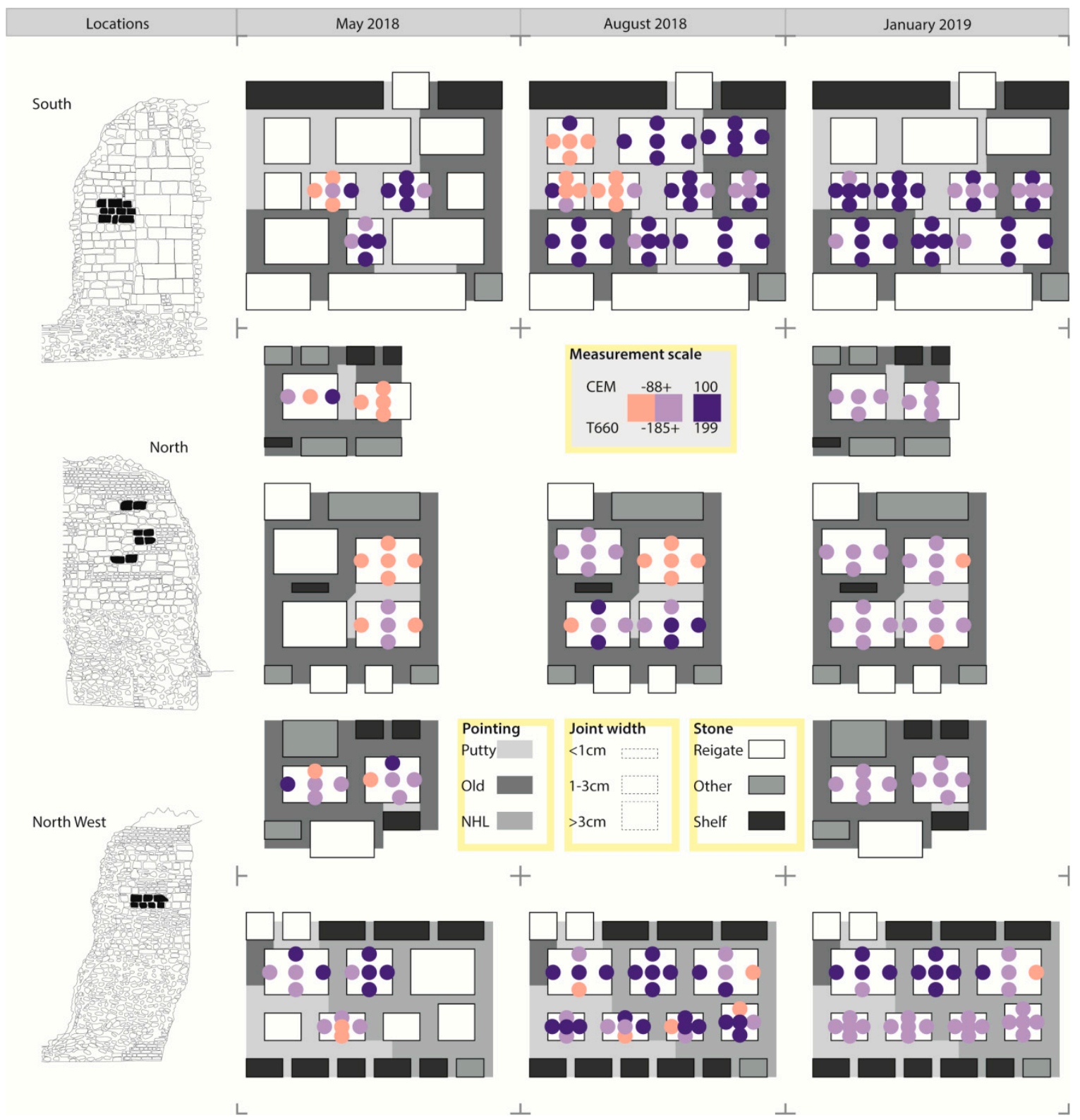

Figure 5. Distribution of CEM (displays readings at 1-100) or T660 (displays at 1-200) moisture meter readings at individual stone scale across three separate surveys, showing low, high and maximum readings for individual Reigate block edges and centres (three measurements per zone). The measurements can provide some indication of differential drying following the recent wetting of the masonry prior to each survey. There is some indication that block edges adjacent to putty mortar are drying more rapidly, but no clear pattern according to mortar type or mortar width. Ambient climate and exposure (both aspect and micro-contextual shelter) provide better indicators.

The good drying conditions in May 2018 and August 2018 are reflected in relatively drier points across several stones in all areas. During the May 2018 survey, some south and north-west facing points appear saturated by the recent wind-driven rain spell; north facing stones, which were sheltered from wind, appear relatively drier. The heavy wind-driven rain spells prior to the August 2018 survey appear to have fully saturated much of the masonry; run-off or deep penetration may be responsible for the wetting of areas not directly exposed to the wind. There is some apparent effect of pointing mortar on drying 
rates across these two surveys. There is some indication that the lime putty mortar is a more effective poultice than the NHL or historic mortars. Approximately half of dry edges are adjacent to lime putty mortars (16 out of 33). There are indications that mortar width also plays a role; in several cases, stones surrounded by both narrow and wide joints have relatively drier edges towards the narrow joints. However, there are also cases in which the opposite is true and cases in which relatively drier edges are adjacent to historic mortar joints. Rather than directly recording an effect of pointing mortar, these results may be reflecting physical differences within individual stones, such as variations in porosity or level of salt contamination. Material context also appears to play a role. Most stone edges directly below overhanging, denser stone or brick are saturated (8 out of 11).

The high ambient relative humidity and poorer drying conditions during the January 2019 survey are reflected in relatively higher, more homogeneous readings across all areas. The recent, light, southerly wind-driven rain spell can explain higher moisture content (MC) across south facing stones. There is little differentiation of MC in relation to type, width, or position of mortar joint. The overall distribution of moisture across all surveys is best explained by exposure to seasonal or diurnal weather patterns; however, individual observations do suggest that pointing mortar can play a subordinate role in regulating the drying of Reigate Stone.

\subsubsection{General Distribution}

In Figure 6, moisture meter measurements from the August 2018, January 2019 and October 2019 surveys are mapped across a larger area of the south facing Reigate Stone ashlar masonry. Results are again grouped into maximum, high and low values. This provides more insight into the effect of seasonal and diurnal weather patterns at the monument scale. During the August 2018 survey, the central core of the masonry is saturated, whilst the outer and upper areas are drier. Run-off from the recent heavy rainfall is likely to have caused a band of increased wetness in high-lying masonry. During the January 2019 survey, lower evaporation rates have resulted in an expansion of the saturated core. In October 2019, the core has receded once again, and recent rainfall is again evident in the upper band. This persistently saturated core is clearly visible as an area of darker stone besides the buttress framed by a band of lighter stone along the outer edge (Figure 1B). It can be explained by the greater volume of masonry in this central part retaining moisture, which as well as due to rain penetration may be the result of rising damp and the high hygroscopicity of Reigate Stone, particularly if contaminated with salts. Observing moisture distribution at the monument scale serves to further highlight some of the factors which can outweigh the role of pointing mortar or individual mortar joints.

\subsection{Surface Hardness Measurements}

\subsubsection{General Distribution}

A series of factorial ANOVA tests were performed (using the aov. function in R) on Reigate Stone surface hardness $(\mathrm{SH})$ data to establish the effect of specific variables on the overall distribution of SH. The objective was to investigate the significance of pointing mortar in determining the $\mathrm{SH}$ of adjacent block edges. ANOVA is a statistical model used to analyse group means within a sample. Factorial ANOVA compares means across two or more independent groups, known as factors. As well as identifying variations in the means of individual factors, factorial ANOVA can be used to identify interactions between factors. The test can therefore evaluate which factor variables or interaction of factor variables significantly affects a response variable (in this case $\mathrm{SH}$ ); a significant variable or interaction is described as a main effect. The factor variables were defined as:

- $\quad$ Date of survey. SH data from the November 2017, August 2018 and January 2019 surveys were included to be representative of different wetting and drying scenarios.

- Aspect. The data were grouped into north and south, to evaluate the role of exposure across the different wetting and drying scenarios. 
- Mortar. The data were grouped into all measurements taken along edges adjoining specific mortar types (i.e., putty, NHL or old mortar) or at the centres of all blocks.

- Block. The data were grouped into all measurements taken on a single block.

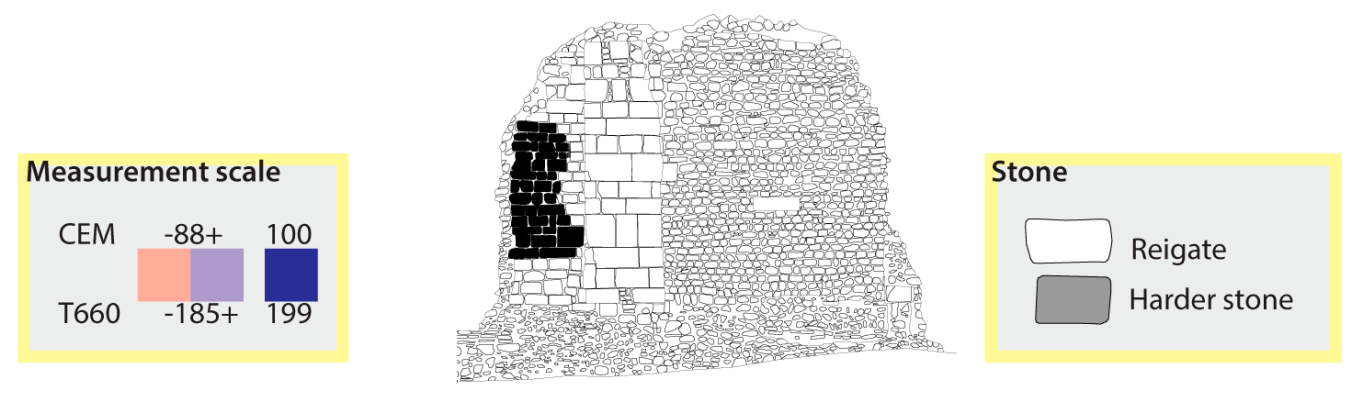

\begin{tabular}{|l|l|l|}
\hline August $2018 \quad$ January $2019 \quad$ & October 2019 \\
\hline
\end{tabular}

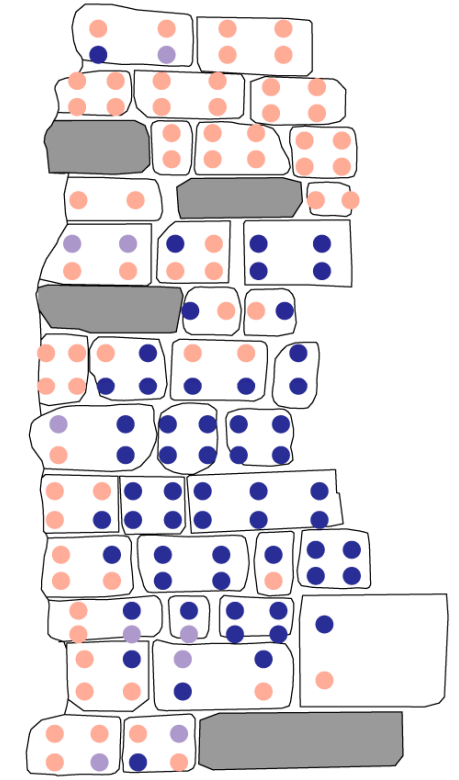

ᄂ

Figure 6. Distribution of moisture meter readings at monument scale across three separate surveys, showing low, high and maximum readings for individual Reigate blocks (one measurement per point). The variation across different seasons highlights the role of macro-scale dynamics, which are likely to outweigh the influence of pointing mortar at individual joints. In particular, the effect of good drying conditions along the edge of the monument (August 2018), and recent rainfall along the top of the monument (October 2019) can be seen.

To enable a meaningful comparison, only measurements taken at the same locations (i.e., on the same block) across all three surveys were included in the dataset. This resulted in over 1500 observations, with approximately 500 individual measurements per survey date across 18 separate blocks, and at least 5 measurements per zone (i.e., individual block edge or centre) during each survey.

Results of the ANOVA tests are summarised in Table 4. An initial test performed on the full dataset (i.e., accounting for each factor and every interaction of multiple factors) did not pass the Levene's test for homogeneity of variance $(p<0.05)$. This indicates that the variance of the different factors is significantly different, and the group means should not be compared using ANOVA. This could be due to the small number of observations per group at factor interactions involving individual points (e.g., comparing 5 measurements at an individual block edge during one survey with 5 measurements of a different block edge at 
another survey). A second factorial ANOVA was performed without block being defined as a factor. This passed the Levene's Test $(p=0.26)$ and the normality assumption. It returned main effects for all the remaining factors (aspect, mortar and date) but no interactions between factors. The Tukey test was performed to find significantly different means within the individual factors. It identified significant differences between NHL edges and block centres $(p=0.003)$, old edges and NHL edges $(p=0.03)$ and putty edges and NHL edges $(p=0.001)$, and also between the January 2019 survey and the other surveys ( $p=0$ for both) (but not between November and August). The dataset was reorganised into subsets taken during each individual survey (November 2017, August 2018 and January 2019) and three further factorial ANOVAs were performed (one per set), with block initially reintroduced as a factor. The August 2018 dataset passed the Levene's test $(p=0.12)$ and the normality assumption. The January 2019 dataset failed the Levene's test $(p=0.005)$; block was removed, and it passed $(\mathrm{p}=0.3)$. The November 2017 dataset was considered borderline on the Levene's test ( $p=0.02)$; block was retained as a factor to enable a more detailed evaluation of its varying effect. Aspect was a main effect across all surveys, but less significant in January 2019. In November 2017 and August 2018 block was also a main effect and there was a significant interaction between mortar and block. Only in August 2018 was mortar type by itself a significant determiner of variation in SH. For this subset, the Tukey test identified differences between NHL edges and block centres, NHL edges and putty edges (both $p=0.001)$, and NHL edges and old edges $(p=0.003)$.

Table 4. Results of factorial analysis of variance (ANOVA) tests on surface hardness data, evaluating effect of individual variables and interactions of variables on distribution of surface hardness measurements. Main effects $(p<0.001)$ in bold, less significant effects $(\mathrm{p}<0.01)$ in italics.

\begin{tabular}{|c|c|c|c|c|c|c|c|c|c|c|c|c|}
\hline & \multicolumn{3}{|c|}{ All Dates } & \multicolumn{3}{|c|}{ November 2017} & \multicolumn{3}{|c|}{ August 2018} & \multicolumn{3}{|c|}{ January 2019} \\
\hline & Df & F Value & $\operatorname{Pr}(>\mathrm{F})$ & Df & F Value & $\operatorname{Pr}(>F)$ & Df & F Value & $\operatorname{Pr}(>\mathrm{F})$ & Df & F Value & $\operatorname{Pr}(>F)$ \\
\hline Date & 2 & 46.32 & $<2 \times 10^{-16}$ & - & - & - & - & - & - & - & - & - \\
\hline Aspect & 1 & 40.43 & $2.67 \times 10^{-10}$ & 1 & 14 & 0.0002 & 1 & 30.34 & $5.50 \times 10^{-8}$ & 1 & 9.18 & 0.0026 \\
\hline Mortar & 3 & 6.28 & 0.0003 & 3 & 0.8 & 0.5 & 3 & 6.72 & 0.0002 & 3 & 1.13 & 0.34 \\
\hline Block* & - & - & - & 16 & 4.65 & $\begin{array}{l}1.38 \times \\
10^{-8 * *}\end{array}$ & 16 & 6.1 & $1.50 \times 10^{-12}$ & - & - & - \\
\hline Date:Aspect & 2 & 1.08 & 0.34 & - & - & - & - & - & - & - & - & - \\
\hline Date:Mortar & 6 & 0.87 & 0.52 & - & - & - & - & - & - & - & - & - \\
\hline Aspect:Mortar & 2 & 1.07 & 0.34 & 2 & 0.71 & 0.49 & 2 & 0.5 & 0.61 & 2 & 0.66 & 0.52 \\
\hline Mortar:Block* & - & - & - & 24 & 2.26 & $0.0007^{* *}$ & 24 & 2.7 & $2.92 \times 10^{-5}$ & - & - & - \\
\hline Date:Aspect:Mortar & 4 & 1.2 & 0.31 & - & - & - & - & - & - & - & - & - \\
\hline Residuals & 1560 & & & 377 & & & 572 & & & 531 & & \\
\hline
\end{tabular}

* Combined dataset and January 2019 dataset did not pass Levene's test $(\mathrm{p}>0.05)$ with block data. ${ }^{* *}$ November 2017 dataset scored $\mathrm{p}=0.02$ on Levene's test. Block data was retained to enable better comparison of overall results.

The results of the factorial ANOVAs suggest $\mathrm{SH}$ is most affected by weather (date of survey) and exposure (aspect); however, adjacent pointing mortar can play a role. The significance of mortar type is linked to seasonal changes, possibly due to different moisture regimes. During the most extreme wetting and drying scenario (August 2018), adjacent mortar type alone was significant in determining $\mathrm{SH}$. Whilst mortar type was not a significant determinant overall following recent wetting and poor drying in November 2017 , it was a good indicator of variation within individual blocks. There was no variation according to mortar type in January 2019, reflecting the lack of recent wetting and more even moisture distribution. When mortar type was significant, NHL edges were responsible for the variation; in particular, there were differences between putty edges and NHL edges. The model has been able to identify some regulatory function in different types of pointing mortar, and their role in controlling changes in SH at different blocks across different moisture regimes. However, caution is required because of underlying differences in the $\mathrm{SH}$ of individual blocks and other factors which were not considered, such as size of block or salt content.

Having established that pointing mortar can in some circumstances be significant in determining the $\mathrm{SH}$ of adjacent block edges, the results were more closely examined. This aimed to identify patterns in changing $\mathrm{SH}$ across the separate surveys which explain 
the variation between NHL edges and other Reigate material groups. In Figure 7, the distribution of individual SH measurements made on different material groups (block centres and edges, and different mortar joints) is plotted across separate surveys. The high SH of NHL mortar is notable, and clearly indicates the hydraulic set. In putty and old mortar joints, the November 2017 and August 2018 surveys return a similar distribution of values, whilst values are lower in January 2019. This pattern is reflected along putty and old mortar block edges, and at the centre of Reigate blocks. These results imply block centres and block edges adjacent to putty or old mortar joints are responding similarly to parameters affecting $\mathrm{SH}$, and a similar response is taking place within the mortar joints themselves. Along NHL mortar joints, SH is higher in August 2018 than in November 2017 or January 2019; along corresponding block edges mean SH decreases across all three surveys. The response pattern of this mortar type is different to that of its adjacent block edges. Caution is necessary in interpreting these results. In mortars in particular, they can be skewed by point measurements taken on harder aggregate. This is a probable reason for the high number of outliers in mortar groups (Figure 7). However, if the changes in SH can be partially attributed to moisture, this could imply that putty and historic mortar joints are performing a suitable role in moisture regulation, by maintaining the block edges in a comparable state to the block centre. The general distribution of $\mathrm{SH}$ values at Reigate centres, putty edges and old edges, and their adjacent mortar joints reflects ambient conditions, with lower values recorded during the wetter, winter survey. The increase in NHL SH from November 2017 to August 2018 could reflect ongoing setting of the hydraulic binder [2]. The corresponding lower SH along NHL block edges may indicate a higher $\mathrm{MC}$, resulting from the denser NHL performing a less effective poulticing.

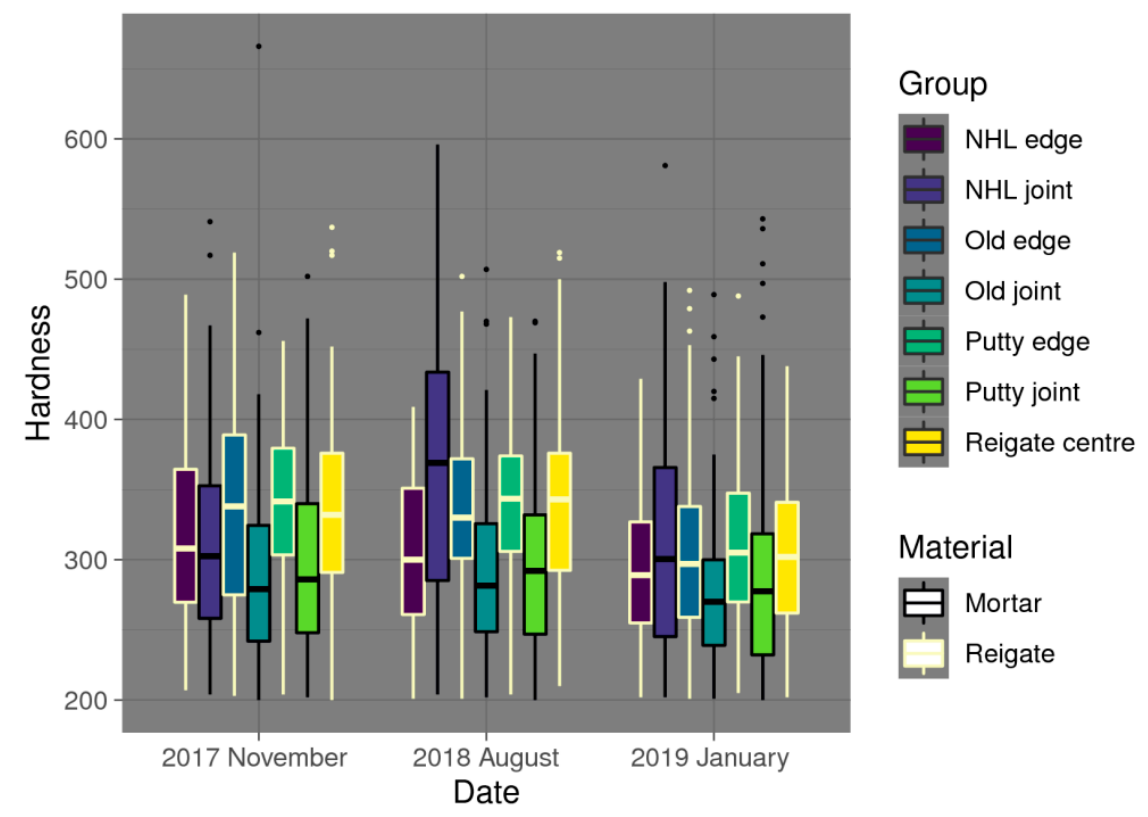

Figure 7. Boxplot of surface hardness measurements across three separate surveys, organised by mortar type and adjacent Reigate block edge (or centre). Central line represents mean value, upper and lower extents of box represent interquartile range (IQR: all measurements within 25th and 75th percentile). Whiskers represent maximum range of measurements less than $1.5 \times \mathrm{IQR}$, outliers are single measurements more than $1.5 \times$ IQR. Only includes data used in ANOVA tests (i.e., measurements taken from same locations across all three surveys). Whilst Reigate centres and edges adjacent to putty and old mortar joints respond similarly to seasonal variation, and corresponding mortar joints follow general pattern, edges adjacent to NHL mortar joints and NHL mortar joints themselves respond differently. 


\subsubsection{Local Distribution}

As indicated by the significance of exposure and individual block properties in the ANOVA, any findings according to generalised material group should be treated with caution and cross examined for the effect of local factors. In Figure 8, SH readings are mapped to locate changes across repeat surveys and localise patterns of change according to mortar type or material context. The August 2018 surveys and January 2019 surveys were chosen to provide the most variable set of results. Inhomogeneities in the distribution of NHL SH during the August 2018 survey reflect the overall increase in SH variance and suggest the rate of hardening or subsequent weathering is susceptible to micro contextual variations such as the width and exposure of the joint. The relatively greater homogeneity of lime putty is visible both across separate surveys and separate areas during the same survey. As when observing the general distribution, some variation may be due to readings taken on aggregate. Average HLD for the different materials measured in these 2 surveys is shown in Table 5 . The results provide further evidence that the lime putty mortar forms reliably soft, elastic joints, but only very few of the measured joints appear to be dangerously hard; these are almost exclusively new NHL joints, with even old, cementitious mortars appearing to have softened. Only in a small number of blocks is SH stable across the entire surface of the stone and both surveys. In most blocks, variation is recorded between separate edges and separate surveys. The distribution of $\mathrm{SH}$ values across individual blocks and different aspects suggests that generalised conclusions on the role of pointing mortar type lose some significance when considering local factors.

Table 5. Total number of surface hardness measurements on different materials, average measurement value, and standard deviation in HLD across survey dates and locations depicted in Figure 8.

\begin{tabular}{cccc}
\hline Material & Total Number & Average (HLD) & StdDev (HLD) \\
\hline NHL joint & 132 & 327.8 & 100.6 \\
Old joint & 293 & 277.5 & 63.9 \\
Putty joint & 216 & 284.3 & 75.9 \\
Reigate & 1186 & 315.0 & 64.2 \\
\hline
\end{tabular}

\subsection{Material Context}

The effect of over 2 years of rainfall and water run-off is clearly visible when comparing photos of the upper masonry taken after the Spring 2017 conservation with those taken in October 2019 (Figure 9). Water run-off channels are visible as areas of algal growth, often following recessed masonry and wide mortar joints. In some cases, these channels also define areas of more advanced decay, which affect stones that lie several meters below the masonry cap. Comparing these with photos taken before 2017 conservation work suggests that the channels have re-formed and continue to concentrate water run-off along the same routes as previously.

Topographical features can also be seen to limit the effect of good pointing and augment the effects of inadequate pointing. The wide joint to the left of WRD3 defines a gully which functions as a bottleneck for one of the main run-off channels along the north-west facing masonry (Figures 9 and 10). It is likely to be saturated following any heavy rainfall and unable to effectively poultice moisture from the adjacent stone, resulting in increased decay along this edge. WRD14 lies on one of the main run-off channels along north-facing masonry. There is evidence of ongoing decay across the entire surface; however, the poorly bonded old mortar joints along the top and left edges have not functioned as a poultice, resulting in a build-up of moisture and algal growth. The joints at the right and bottom edge, whilst in the same cementitious mortar, have remained in bond and appear to perform a more effective poultice. WRD40 also sits along a run-off channel. Besides algal growth on the centre of the stone surface, there appears to have been greater ongoing decay at the intersection between the upper edge and the more permanently saturated portion of the joint, which may not have been able to regulate 
moisture properly, despite being in repointed lime putty. Observing these changes since the most recent cycle of conservation indicates that water run-off is key to the emergence of decay pathways in highly exposed masonry. During the most recent conservation work, it was deemed too risky to remove the hard, cementitious mortar cap, which had consistent cover over the masonry and was locked rigid. The results of this study suggest that given the exposed nature of the Wardrobe Tower, the cap contributes to ongoing decay and alternative solutions, such as roofing or replacement with soft, vegetation capping should be considered.

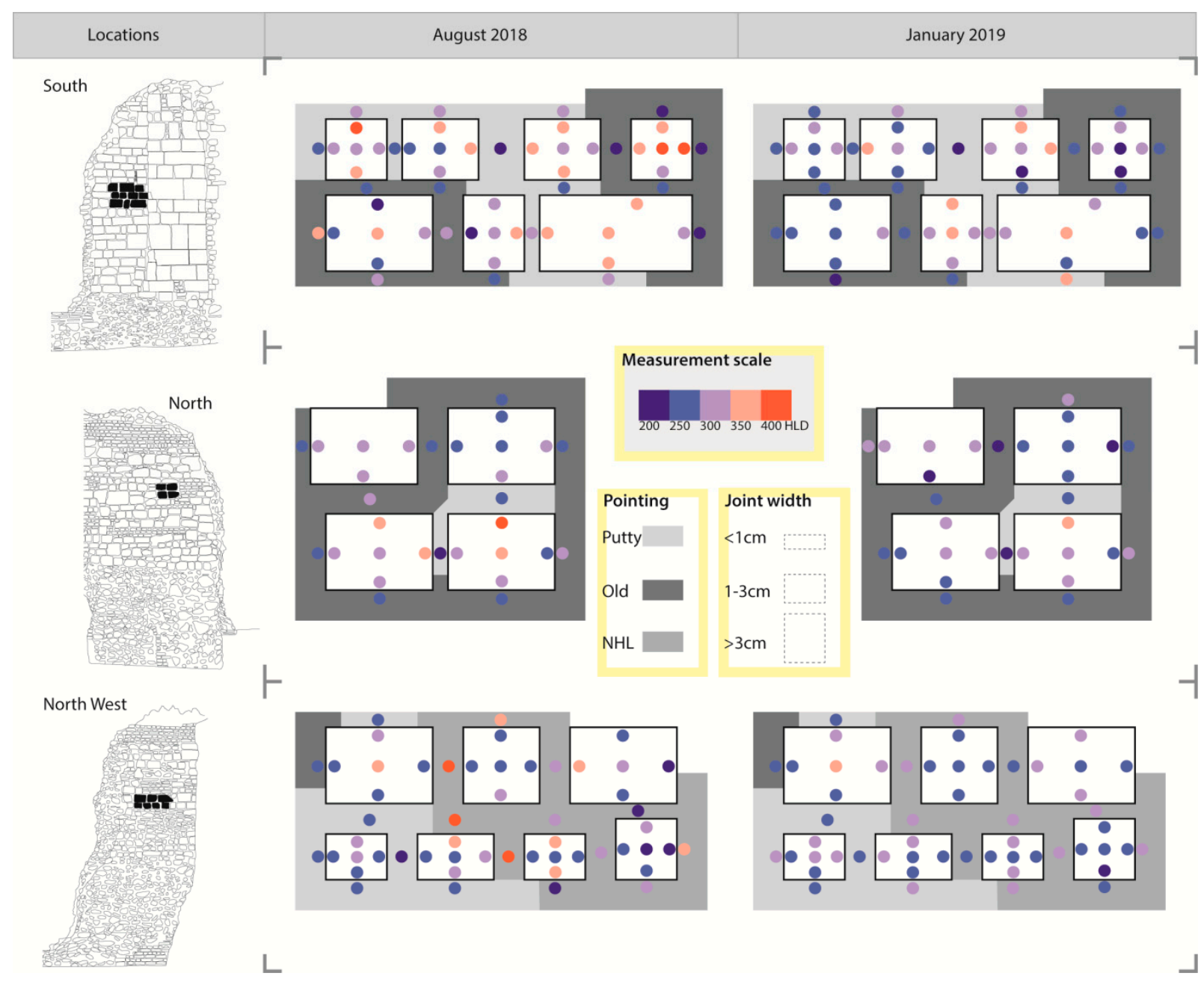

Figure 8. Distribution of surface hardness measurements at individual stone scale across two separate surveys, showing HLD for individual Reigate block edges and centres (5-8 measurements per point). Local variation across individual blocks irrespective of adjacent mortar type, and lack of clear patterns according to mortar type, demonstrate the caution is necessary when interpreting the generalised findings made in the ANOVA test. Local factors, such as micro-contextual shelter and joint width may override any controlling effect of the mortar type.

There are few visual indications conclusively linking pointing mortar with ongoing decay. Generally, these can be attributed more to contextual or morphological features than mortar type. WRD16 for example, which was in a highly decayed condition in November 2017, has continued to decay rapidly despite repointing with lime putty (Figure 10). This is likely to be due to the wide joint below the stone forming a shelf, which may result in moisture pooling and inhibit the poulticing function of the mortar. Decay to the exposed right edge of WRD54 could be explained by the lack of adjacent mortar and poulticing effect, with moisture fluctuations and salt crystallisation taking place at the surface of the arris. In cases where decay appears to progress more rapidly along NHL or old, cementitious joints, such as WRD24 (left edge) and WRD30 (top left), pre-existing decay features appear 
to have played a role. USB microscopy identified emergent biological growth on several poorly bonded, new NHL joints (Figure 11). However, there were both well and poorly bonded joints along putty, NHL and historic pointing, indicating that soft or hard mortar types are not a guarantee for good or poor long-term bonds respectively. The timescale of the project and lack of uniformity between initial conditions along block edges makes it hard to assess the impact of pointing mortar on specific stones.
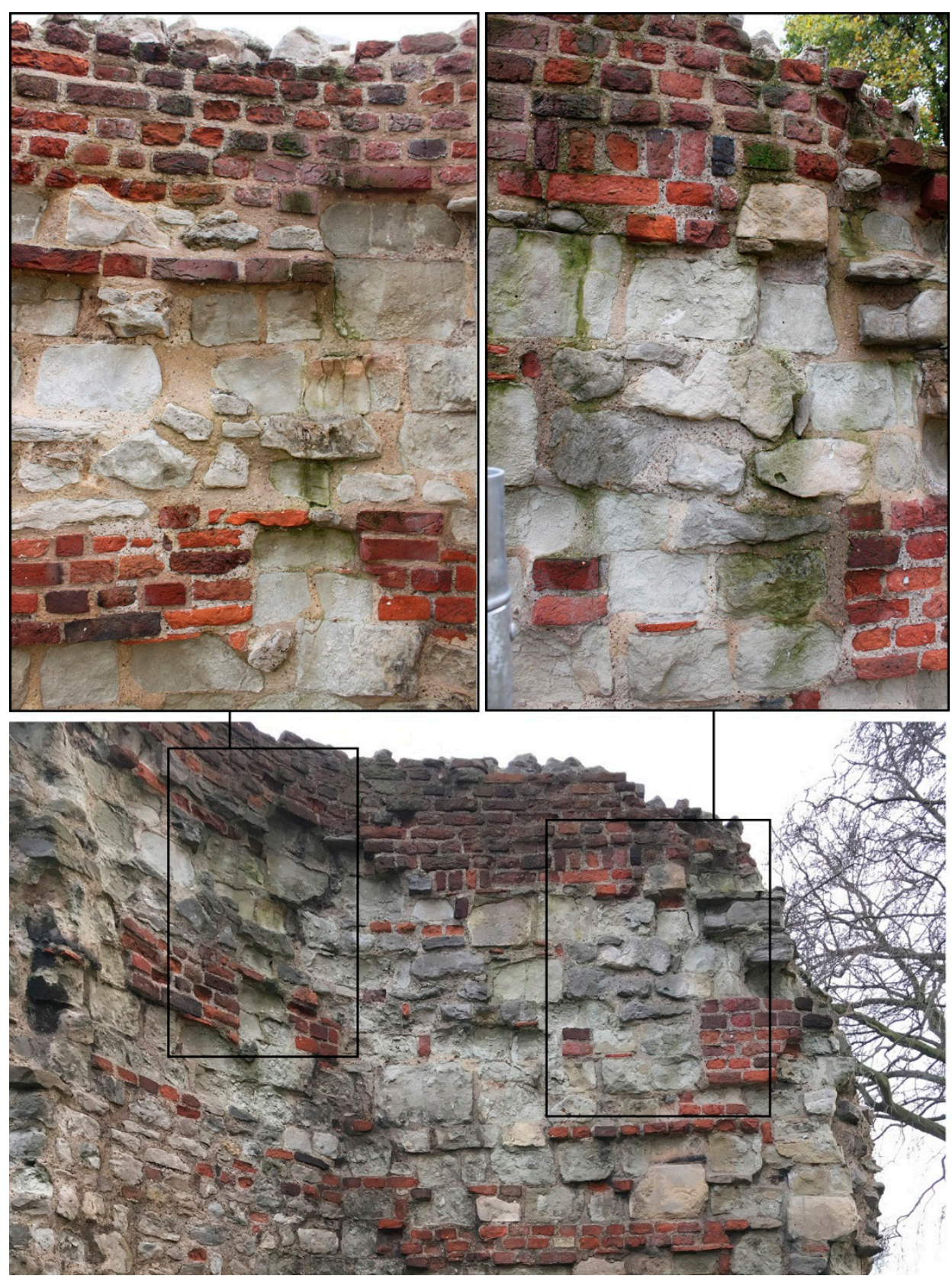

Figure 9. Parts of north facing masonry included in Wardrobe Tower photographed shortly before 2017 conservation (below) and in October 2019 (above). Water run-off channels have reformed, their location corresponds to past decay features. 

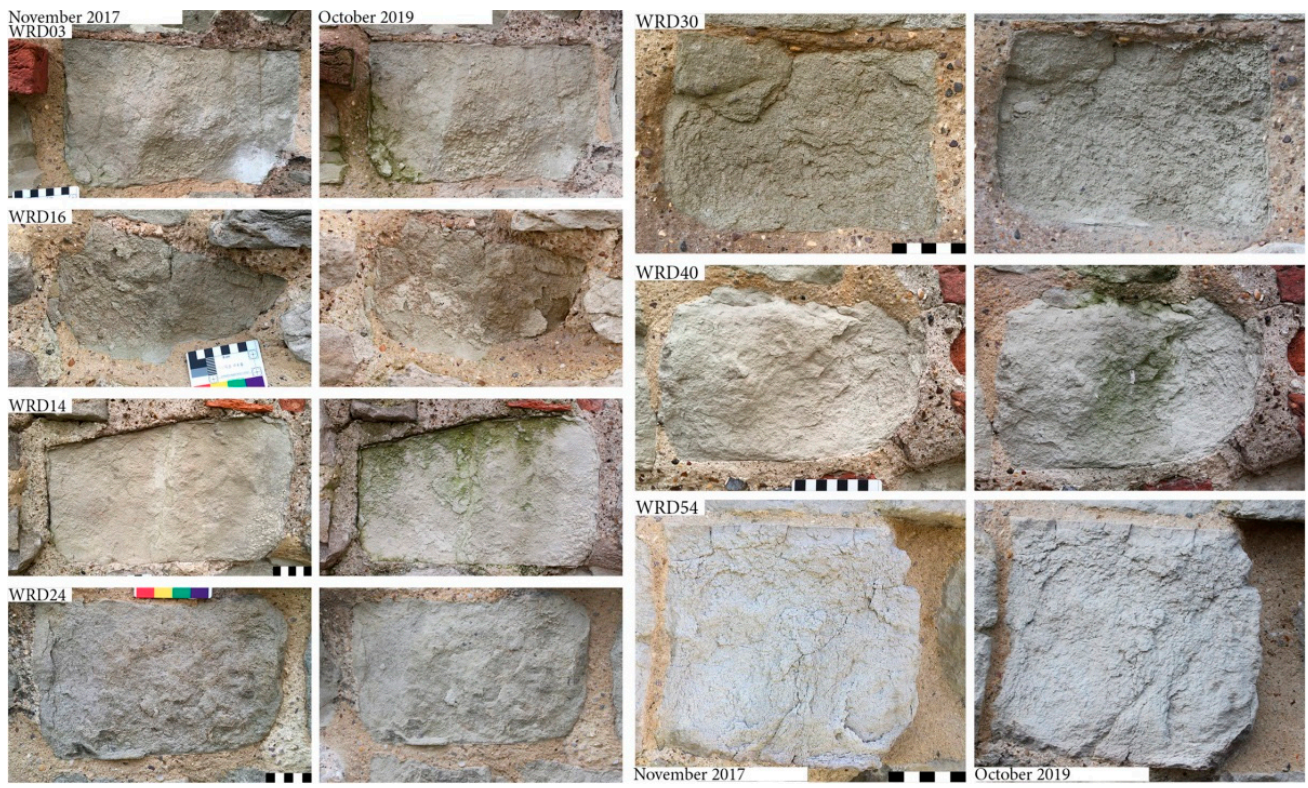

Figure 10. Selection of individual Reigate Stone blocks photographed in November 2017 and October 2019. Some signs of ongoing decay can be associated with inadequate pointing (e.g., WRD16 and WRD14), some can be associated with exposure and macro-context (e.g., WRD03, WRD40, WRD54). There are few examples of ongoing decay which can be more closely associated with type of pointing mortar (WRD24, WRD30).

\subsection{Synthesis}

This research set out to establish how best NDT can be used to determine the effect of pointing mortar on surrounding masonry. It aimed to establish whether pointing mortar constituted a measurable control on the decay of the Wardrobe Tower; specifically, whether there was a discernible difference between the NHL and lime putty recipes used in 2017 conservation work. The results provide some evidence that pointing mortar does have a measurable effect on adjacent block edges. In particular, ANOVA tests of surface hardness distribution according to different material categories across different surveys suggest that when viewing the overall distribution of measurements, harder, new NHL joints trap moisture, whilst softer putty joints enable a response that is similar to the centre of Reigate Stone blocks. Old, eminently hydraulic pointing mortar performed similarly to new putty. Viewed locally, there are some indications of better moisture regulation along putty joints; however, these are outweighed by a range of other contextual factors, such as the location of an individual block in relation to the monument, local topography forming shelves or shelters, and the width of the joint.

The approach used here involved long-term data collection across multiple surveys using several NDT. Constraints of working in the field at a large heritage site were a complicating factor on gathering comparable data across multiple surveys; however, whilst the NDT did not establish clear patterns according to pointing mortar type when the data were viewed spatially, this approach enabled a multi-scale evaluation of the data. Combining local observations made with relatively small datasets with the statistical analysis of larger datasets, whilst incorporating more traditional surveying techniques such as photographic documentation, identified controlling effects on the decay of the Wardrobe Tower. These included moisture regulation at the monument scale, most notably water run-off during heavy rainfall, which compounds efforts to adequately re-point the masonry and contributes to ongoing cycles of decay. The use of portable, relatively accessible devices demonstrated here provides a model for incorporating such techniques into regular maintenance schedules. Alongside existing approaches, such as test-walls and laboratory experiments, this can monitor the role of pointing mortar within the wider system dynamics of masonry decay. 

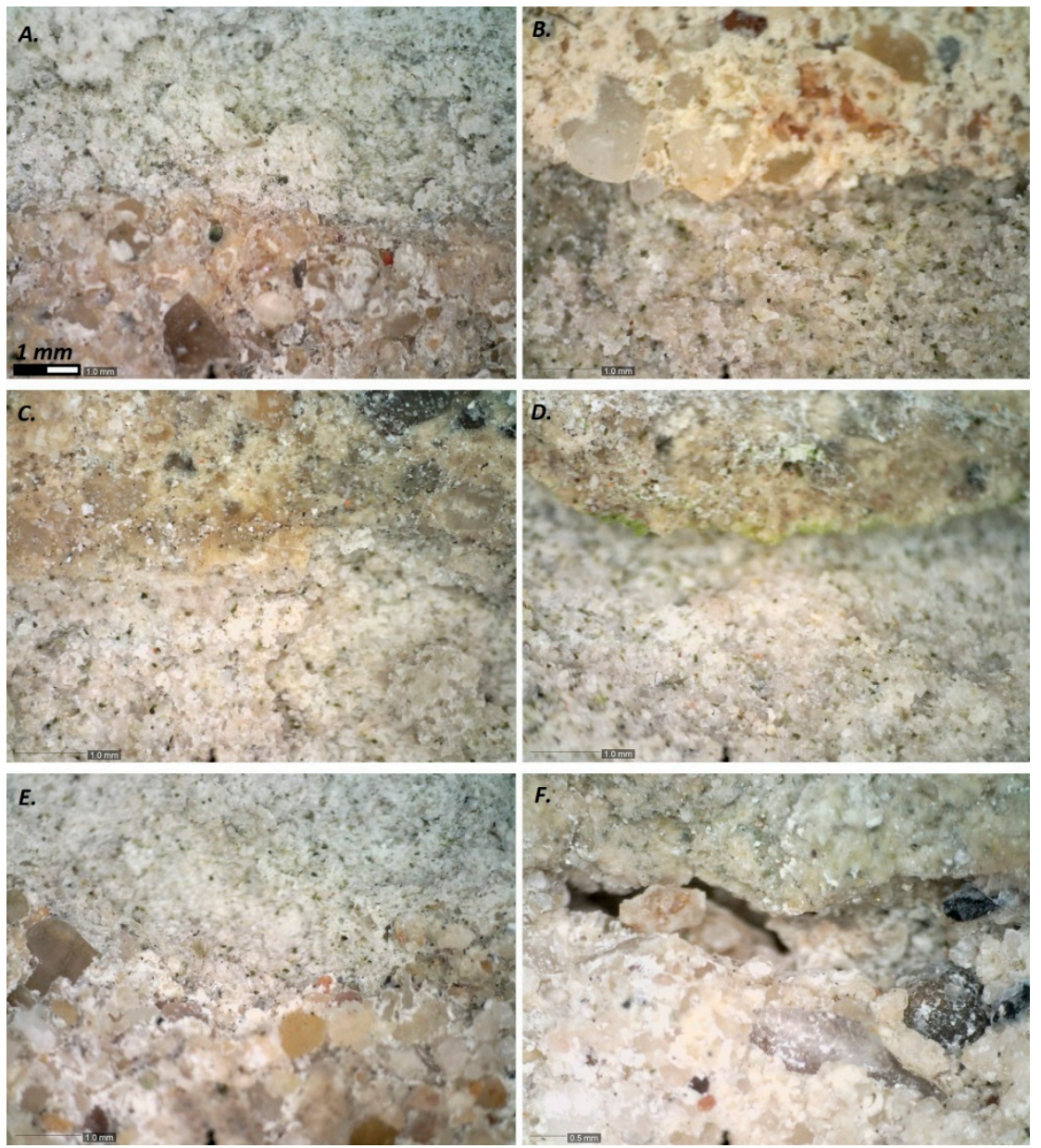

Figure 11. USB micrographs showing: (A) well bonded putty mortar (WRD12); (B) poorly bonded putty mortar (WRD27); (C) well bonded NHL mortar (WRD29); (D) poorly bonded NHL mortar with algal growth (WRD30); (E) well bonded old mortar (WRD53); (F) and poorly bonded old mortar (WRD39). (scale bar 1mm).

\section{Conclusions}

This study has shown that combining NDT in repeated, in situ survey campaigns can deliver useful data for assessing moisture dynamics in historic masonry. Moisture content (MC) as measured using capacitance moisture meters on Reigate Stone surfaces was divided into three broad regions to assess change in response to environmental conditions at different spatial resolutions. Surface hardness $(\mathrm{SH})$ measurements were taken on Reigate Stone and pointing mortar. Changes in $\mathrm{SH}$ are likely to reflect several parameters. Given the inaccuracy of capacitance meters as MC approaches saturation, and with careful interpretation, $\mathrm{SH}$ measurements taken at the same zone across several campaigns can provide a useful indicator of relative changes to MC. This long-term, parametric, multiscalar approach tracked changes in moisture distribution at the Wardrobe Tower, with different types of pointing mortar identified as a factor in the moisture dynamics of corresponding stone edges.

Non-destructively assessing the impact of pointing mortar on historic masonry in situ is highly complex, due to factors such as site logistics, inherent variability in the masonry system and the limitations of NDT. However, whilst controlled 'test-wall' experiments may be more suited to identifying specific issues pertaining to the mortar itself, these sorts of tests can identify additional parameters that must be considered during the design of holistic conservation strategies. This study highlighted the importance of 
micro-contextual features, such as overhangs or gullies. These could be incorporated in future 'test-wall' experiments.

Whilst the correct functioning of pointing mortar can mitigate stone decay, repointing can only be one aspect of a holistic preventive conservation strategy. Additional measures are necessary not only to protect vulnerable building stones, but also to enable correct functioning of the pointing mortar. In unsuitable conditions, even suitable mortar recipes can contribute to, rather than arrest stone decay. This can include the channeling or pooling of moisture along joints during rainfall, or the rapid decay of the mortar, which can result in inadequate bonding with the stone or chemical leaching.

Regular mortar maintenance and repointing schedules are necessary long-term stone conservation strategies; however, the immediate impact on vulnerable building stones of depointing hard mortars needs to be considered alongside the mid-term benefits of repointing according to current best practice. This study found that initially inappropriate mortar recipes used in 20th century conservation work at the Wardrobe Tower have in some cases weathered sympathetically. Repointing a damaged area of masonry without mitigating against ongoing decay mechanisms such as driving rain, may drive a cycle of decline by which weakened stone arrises are removed, mortar joints widen, and moisture penetration increases. Furthermore, the mortar may itself have historic or material value, complicating removal even if it is damaging to stonework. Decisions on the specific repointing of a mortar joint must be taken on a case-by-case basis.

Sustainable repointing requires tailored strategies, with several different approaches, and potentially different mortar recipes, for the individual joints of a single building. The results of this study suggest that, whilst ongoing work is needed to better define a specific protocol, accessible NDT used across repeat surveys can provide a meaningful assessment of the relationship between stone blocks and adjacent mortar joints. Localised findings using handheld devices will be most effective in conjunction with more traditional surveying methods, such as photographic documentation and holistic, structural appraisal. Taken together, the techniques presented here can provide detailed long-term monitoring of moisture regulation in masonry structures, which could be used to validate computational modelling and support targeted decision making in repointing and general conservation strategies.

In situations where repointing is appropriate and once measures have been taken to protect the correct functioning of the pointing mortar, the evidence presented here suggests that the choice of mortar recipe is important in Reigate Stone conservation. Although conclusions are difficult in the 2-year timeframe of the project, there are early indications that the lime putty mortar is weathering more sympathetically and drawing moisture more effectively than the NHL. However, ongoing rapid decay following repointing with lime putty, noted at the Wardrobe Tower and elsewhere, suggests that further improvements in recipe and technique could be of benefit.

Author Contributions: Conceptualization, M.M., H.V., C.V. and I.A.; methodology, M.M., H.V. and I.A.; writing-original draft preparation, M.M.; writing—review and editing, M.M., H.V., C.V. and I.A.; visualization, M.M.; supervision, H.V., C.V. and I.A; funding acquisition, H.V. and C.V. All authors have read and agreed to the published version of the manuscript.

Funding: This work was supported by funding from the Engineering and Physical Sciences Research Council (EPSRC) and Historic Royal Palaces (HRP) as a part of the Centre for Doctoral Training in Science and Engineering in Arts, Heritage and Archaeology (SEAHA) [grant number: EP/L016036/1].

Acknowledgments: The authors would like to thank Johannes Weber from the University of Applied Arts, Vienna, for kind help with analysing the historic mortars; current and former colleagues at the University of Oxford Lucie Fusade and Katrin Wilhelm for advice on the non-destructive testing protocol, and Martin Coombes for advice on the statistical analysis; James Campen from Carden and Godfrey Architects, Manjit Phull and the team from Sally Strachey Conservation, and current and former colleagues from Historic Royal Palaces, particularly Alex Attelsey, Ayez Syed and Preethi Narasimhan, for facilitating the field surveys. The authors would also like to thank ten anonymous reviewers for their feedback on different drafts of this paper. 
Conflicts of Interest: The authors declare no conflict of interest.

\section{References}

1. Torney, C.; Forster, A.M.; Szadurski, E.M. Specialist 'restoration mortars' for stone elements: A comparison of the physical properties of two stone repair materials. Herit. Sci. 2014, 2, 1. [CrossRef]

2. Fusade, L.; Viles, H.A. A comparison of standard and realistic curing conditions of natural hydraulic lime repointing mortar for damp masonry: Impact on laboratory evaluation. J. Cult. Herit. 2019, 37, 82-93. [CrossRef]

3. Elert, K.; Rodriguez-Navarro, C.; Pardo, E.S.; Hansen, E.; Cazalla, O. Lime mortars for the conservation of historic buildings. Stud. Conserv. 2002, 47, 62-75.

4. Forster, A. Hot-lime mortars: A current perspective. J. Archit. Conserv. 2004, 10, 7-27. [CrossRef]

5. Fusade, L.; Viles, H.; Wood, C.; Burns, C. The effect of wood ash on the properties and durability of lime mortar for repointing damp historic buildings. Constr. Build. Mater. 2019, 212, 500-513. [CrossRef]

6. Erkal, A.; D'Ayala, D. Laboratory testing of non-standard original historic building materials and related implications for conservation. Q. J. Eng. Geol. Hydrogeol. 2015, 48, 15-28. [CrossRef]

7. Michette, M.; Viles, H.; Vlachou, C.; Angus, I. The many faces of Reigate Stone: An assessment of variability in historic masonry based on Medieval London's principal freestone. Herit. Sci. 2020, 8, 80. [CrossRef]

8. Sowan, P.W. Firestone and hearthstone mines in the Upper Greensand of east Surrey. Proc. Geol. Assoc. 1975, 86, 571-591. [CrossRef]

9. Michette, M.; Viles, H.; Vlachou-Mogire, C.; Angus, I. Assessing the Long-term Success of Reigate Stone Conservation at Hampton Court Palace and the Tower of London. Stud. Conserv. 2020, 65, 225-232. [CrossRef]

10. Erkal, A.; D'Ayala, D.; Sequeira, L. Assessment of wind-driven rain impact, related surface erosion and surface strength reduction of historic building materials. Build. Environ. 2012, 57, 336-348. [CrossRef]

11. Sanderson, R.; Garner, K. Conservation of Reigate Stone at Hampton Court Palace and HM Tower of London. J. Archit. Conserv. 2001, 7, 7-23. [CrossRef]

12. Orr, S.A.; Young, M.; Stelfox, D.; Curran, J.; Viles, H. Wind-driven rain and future risk to build heritage in the United Kingdom: Novel metrics for characterising rain spells. Sci. Total Environ. 2018, 640, 1098-1111. [CrossRef] [PubMed]

13. Fusade, L.; Orr, S.A.; Wood, C.; O’Dowd, M.; Viles, H. Drying response of lime-mortar joints in granite masonry after an intense rainfall and after repointing. Herit. Sci. 2019, 7, 38. [CrossRef]

14. Charola, A.E. Salts in the deterioration of porous materials: An overview. J. Am. Inst. Conserv. 2000, 39, 327-343. [CrossRef]

15. Wangler, T.; Scherer, G.W. Clay swelling mechanism in clay-bearing sandstones. Environ. Geol. 2008, 56, 529-534. [CrossRef]

16. Wiggins, D. Traditional lime mortars and masonry preservation. J. Build. Limes Forum 2017, 24, $28-37$.

17. Henry, A.; Stewart, J. Mortars, Renders and Plasters. In Practical Building Conservation, 1st ed.; Henry, A., Stewart, J., Eds.; Historic England: Swindon/London, UK, 2011.

18. Maurenbrecher, P. RILEM TC 203-RHM: Repair mortars for historic masonry: Requirements for repointing mortars for historic masonry. Mater. Struct. 2012, 45, 1303-1309.

19. Weber, J.; Gadermayr, N.; Bayer, K.; Hughes, D.; Kozlowski, R.; Stillhammerova, M.; Vyskocilova, R. Roman cement mortars in Europe's architectural heritage of the 19th century. In Natural Cement; ASTM International: West Conshohocken, PA, USA, 2008.

20. Urquhart, D.C.M.; Young, M.E.; MacDonald, J.; Jones, M.S.; Nicholson, K.A. Aberdeen granite buildings: A study of soiling and decay. In Processes of Urban Stone Decay; Routledge: London, UK, 1996; p. 76.

21. McCabe, S.; Smith, B.J.; Warke, P.A. A legacy of mistreatment: Conceptualizing the decay of medieval sandstones in NE Ireland. Geol. Soc. Lond. Spec. Publ. 2010, 333, 87-100. [CrossRef]

22. Odgers, D.; Henry, A.; Martin, B.; Wood, C. Stone by English Heritage. In Practical Building Conservation; Historic England: Swindon/London, UK, 2012.

23. McCann, D.M.; Forde, M.C. Review of NDT methods in the assessment of concrete and masonry structures. NDT E Int. 2001, 34, 71-84. [CrossRef]

24. Moropoulou, A.; Labropoulos, K.C.; Delegou, E.T.; Karoglou, M.; Bakolas, A. Non-destructive techniques as a tool for the protection of built cultural heritage. Constr. Build. Mater. 2013, 48, 1222-1239. [CrossRef]

25. Madariaga, J.M.; Maguregui, M.; De Vallejuelo, S.F.O.; Knuutinen, U.; Castro, K.; Martinez-Arkarazo, I.; Pitarch, A. In situ analysis with portable Raman and ED-XRF spectrometers for the diagnosis of the formation of efflorescence on walls and wall paintings of the Insula IX 3 (Pompeii, Italy). J. Raman Spectrosc. 2014, 45, 1059-1067. [CrossRef]

26. Arrizabalaga, I.; Gómez-Laserna, O.; Carrero, J.A.; Bustamante, J.; Rodríguez, A.; Arana, G.; Madariaga, J.M. Diffuse reflectance FTIR database for the interpretation of the spectra obtained with a handheld device on built heritage materials. Anal. Methods 2015, 7, 1061-1070. [CrossRef]

27. Drdácký, M.; Slížková, Z. Enhanced affordable methods for assessing material characteristics and consolidation effects on stone and mortar. J. Geophys. Eng. 2013, 10, 064005. [CrossRef]

28. Franković, M.; Novaković, N.; Matović, V. Damage quantification of built stone on Dark Gate (Belgrade, Serbia): Sample of damage index application for decay rate evaluation. Environ. Earth Sci. 2015, 73, 6181-6193. [CrossRef]

29. Hendrickx, R. Using the Karsten Tube to estimate water transport parameters of porous building materials. Mater. Struct. 2012, 46, 1309-1320. [CrossRef] 
30. Scrivano, S.; Gaggero, L. Non-invasive analytical technique to address water uptake on stone surfaces: The implemented Contact Sponge Method (i-CSM). J. Cult. Herit. 2017, 28, 9-15. [CrossRef]

31. Scrivano, S.; Gaggero, L.; Gonzalez, A.Y.; Aguilar, J.G. Assessing surface weathering by revision and implementation of the peeling-test: In situ sampling and integrated analyses. J. Cult. Herit. 2017, 27, 88-96. [CrossRef]

32. Viles, H.; Goudie, A.; Grab, S.; Lalley, J. The use of the Schmidt Hammer and Equotip for rock hardness assessment in geomorphology and heritage science: A comparative analysis. Earth Surf. Process. Landf. 2011, 36, 320-333. [CrossRef]

33. Wilhelm, K.; Viles, H.; Burke, Ó. Low impact surface hardness testing (Equotip) on porous surfaces-advances in methodology with implications for rock weathering and stone deterioration research. Earth Surf. Process. Landf. 2016, 41, 1027-1038. [CrossRef]

34. Eklund, J.A.; Zhang, H.; Viles, H.A.; Curteis, T. Using handheld moisture meters on limestone: Factors affecting performance and guidelines for best practice. Int. J. Archit. Herit. 2013, 7, 207-224. [CrossRef]

35. Camuffo, D.; Bertolin, C. Towards standardisation of moisture content measurement in cultural heritage materials. $e$-Preserv. Sci. 2012, 9, 23-35.

36. Aoki, H.; Matsukura, Y. A new technique for non-destructive field measurement of rock-surface strength: An application of the Equotip hardness tester to weathering studies. Earth Surf. Process. Landf. J. Br. Geomorphol. Res. Group 2007, 32, 1759-1769. [CrossRef]

37. Yilmaz, N.G. The influence of testing procedures on uniaxial compressive strength prediction of carbonate rocks from Equotip hardness tester (EHT) and proposal of a new testing methodology: Hybrid dynamic hardness (HDH). Rock Mech. Rock Eng. 2013, 46, 95-106. [CrossRef]

38. Fort, R.; de Buergo, M.A.; Perez-Monserrat, E.M. Non-destructive testing for the assessment of granite decay in heritage structures compared to quarry stone. Int. J. Rock Mech. Min. Sci. 2013, 61, 296-305. [CrossRef]

39. Wilhelm, K.; Viles, H.; Burke, O.; Mayaud, J. Surface hardness as a proxy for weathering behaviour of limestone heritage: A case study on dated headstones on the Isle of Portland, UK. Environ. Earth Sci. 2016, 75, 931. [CrossRef]

40. Orr, S.A.; Young, M.; Stelfox, D.; Leslie, A.; Curran, J.; Viles, H. An 'isolated diffusion' gravimetric calibration procedure for radar and microwave moisture measurement in porous building stone. J. Appl. Geophys. 2019, 163, 1-12. [CrossRef]

41. Viles, H.A. Durability and conservation of stone: Coping with complexity. Q. J. Eng. Geol. Hydrogeol. 2013, 46, 367-375. [CrossRef]

42. Michette, M.; Bichlmair, S.; Kilian, R. Diagnosing Decay Mechanisms at the Porta Nocera Necropolis, Pompeii: The First Step towards Effective Preventive Conservation. Stud. Conserv. 2018, 63 (Suppl. 1), 195-202. [CrossRef]

43. Sass, O.; Viles, H.A. Wetting and drying of masonry walls: 2D-resistivity monitoring of driving rain experiments on historic stonework in Oxford, UK. J. Appl. Geophys. 2010, 70, 72-83. [CrossRef]

44. De Boever, W.; Bultreys, T.; Derluyn, H.; Van Hoorebeke, L.; Cnudde, V. Comparison between traditional laboratory tests, permeability measurements and CT-based fluid flow modelling for cultural heritage applications. Sci. Total Environ. 2016, 554, 102-112. [CrossRef]

45. Tatton-Brown, T. Medieval building stone at the Tower of London. Lond. Archaeol. 1991, 6, 361.

46. Compton, C.H. Recent Discoveries at the Tower of London. J. Br. Archaeol. Assoc. First Ser. 1881, 37, 279-284. [CrossRef]

47. Ateeq, H.; Roberts, G. Statement of Significance: Wardrobe Tower, Tower of London; unpublished report; Historic Royal Palaces: London, UK, 2017.

48. Parnell, G. Book of the Tower of London; BT Batsford: London, UK, 1993.

49. Drdácký, M.; Lesák, J.; Niedoba, K.; Valach, J. Peeling tests for assessing the cohesion and consolidation characteristics of mortar and render surfaces. Mater. Struct. 2015, 48, 1947-1963. [CrossRef]

50. Michette, M.; Viles, H.; Vlachou, C.; Angus, I. Bellweathered: Reigate Stone Decay Mechanisms at the Bell Tower, Tower of London. Monum. Monum. 2019, 2019, 53-64.

51. Wilhelm, K.; Viles, H.; Burke, Ò. The influence of salt on handheld electrical moisture meters: Can they be used to detect salt problems in porous stone? Int. J. Archit. Herit. 2016, 10, 735-748. [CrossRef]

52. Desarnaud, J.; Kiriyama, K.; Bicer Simsir, B.; Wilhelm, K.; Viles, H. A laboratory study of Equotip surface hardness measurements on a range of sandstones: What influences the values and what do they mean? Earth Surf. Process. Landf. 2019, 44, 1419-1429. [CrossRef] 